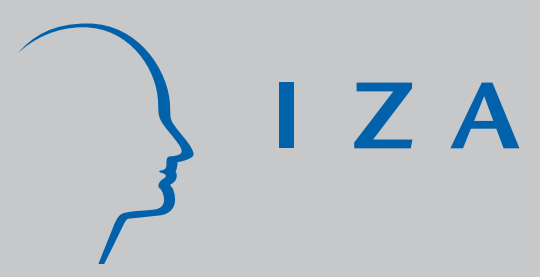

IZADP No. 2356

Intentions to Return of Undocumented Migrants: Illegality as a Cause of Skill Waste

Nicola D. Coniglio

Giuseppe De Arcangelis

Laura Serlenga

October 2006 


\title{
Intentions to Return of Undocumented Migrants: Illegality as a Cause of Skill Waste
}

\author{
Nicola D. Coniglio \\ Norwegian School of Economics and Business Administration (NHH) \\ and University of Bari
}

Giuseppe De Arcangelis

University of Rome "La Sapienza"

Laura Serlenga

University of Bari

and IZA Bonn

Discussion Paper No. 2356

October 2006

IZA

P.O. Box 7240

53072 Bonn

Germany

Phone: +49-228-3894-0

Fax: +49-228-3894-180

E-mail: iza@iza.org

Any opinions expressed here are those of the author(s) and not those of the institute. Research disseminated by IZA may include views on policy, but the institute itself takes no institutional policy positions.

The Institute for the Study of Labor (IZA) in Bonn is a local and virtual international research center and a place of communication between science, politics and business. IZA is an independent nonprofit company supported by Deutsche Post World Net. The center is associated with the University of Bonn and offers a stimulating research environment through its research networks, research support, and visitors and doctoral programs. IZA engages in (i) original and internationally competitive research in all fields of labor economics, (ii) development of policy concepts, and (iii) dissemination of research results and concepts to the interested public.

IZA Discussion Papers often represent preliminary work and are circulated to encourage discussion. Citation of such a paper should account for its provisional character. A revised version may be available directly from the author. 
IZA Discussion Paper No. 2356

October 2006

\section{ABSTRACT}

\section{Intentions to Return of Undocumented Migrants: Illegality as a Cause of Skill Waste}

In this paper we show that highly skilled undocumented migrants are more likely to return home than migrants with low or no skills when illegality causes "skill waste", i.e. when illegality reduces the rate of return of individual capabilities (i.e. skills and human capital) in both the labor and the financial markets of the country of destination. This proposition is first illustrated in a simple life-cycle framework, where illegality acts as a tax on skills, and then is tested on a sample of apprehended immigrants that crossed unlawfully the Italian borders in 2003. The estimation confirms that the intention to return to the home country is more likely for highly skilled than low-skill illegal immigrants. The presence of migration networks in the destination country may lower the skill-waste effect. The empirical result of this paper contrasts with the common wisdom on return decisions of legal migrants, according to which low-skill individuals are more likely to go back home rather than highly skilled migrants.

JEL Classification: F22, C25

Keywords: $\quad$ illegal migration, labor skills, survey data

Corresponding author:

Laura Serlenga

Dipartimento di Scienze Economiche

University of Bari

Via C. Rosalba n. 53

70124 Bari

Italy

E-mail: laura.serlenga@dse.uniba.it

\footnotetext{
${ }^{*}$ We wish to thank Maria Concetta Chiuri, Cecile Defoort, Giovanni Ferri, Hillel Rapaport, Alessandra Venturini and participants at the SIUTE seminar of the University of Lille 1 for useful discussions on preliminary versions of this paper. Piero Cipollone and Christian Dustmann also offered useful insights at the AIEL 2005 Meeting where an earlier version was presented. The usual disclaimer applies.
} 


\section{Introduction}

The debate on illegal ${ }^{1}$ migration in the developed world is capturing a great deal of public attention. The mounting dimension of the phenomenon is a direct consequence of the tightening of immigration laws in most OECD countries. In fact, instead of decreasing the size of immigration flows, this policy seems to have shifted the balance from legal to undocumented (or illegal) migration. According to recent estimates of the US "Immigration and Naturalization Service" the total unauthorized immigrant population residing in the United States in January 2000 was about 7.0 million. The estimated number of illegal immigrants entering annually the US has risen from 350,000 in 1990 to 500,000 in 1999. Estimates of illegal migration flows to Europe (EU-15) in 2001 are up to 650,000 according to a recent study by Jandl (2004) (100,000 of them in Italy). ${ }^{2}$

In this paper, we aim to shed some light on the return of undocumented migrants, in particular by using their return intentions. Illegality plays a key role since it causes skill waste, i.e. illegality impinges the positive outcome of skills on both income and savings of the migrant and acts like a tax.

The starting point of this paper is indeed the stark difference between undocumented and legal migrants. As generally acknowledged, although one of the most common motives for migration is the necessity to accumulate assets (which will be subsequently employed in productive activities) an illegal entrant is generally less capable of fully exploiting her skills and human capital. Moreover, the illegal status hinders the migrant's access to many markets and institutions in the host country (including banks for deposits or financial institutions for other types of savings), which are instead fully available to legal migrants. Being illegal may make individual skills even less effective than in the home country, as the illegal migrant has to resort uniquely to the shadow economy. As a consequence, the skill waste, typically related to the illegal status, is particularly strong for those who are the most skilled and educated among the illegal entrants. Given this, it would be natural to expect that the opportunity cost of returning to the country of origin be substantially lower for the skilled individuals than for the unskilled ones.

The contribution of this paper is twofold: first, we consider a life-cycle framework to link the skill endowment to the return decision of illegal migrants; second, thanks to the availability of an unique data set on Italian undocumented immigrants we empirically test the main implications of our theoretical specification.

In particular, the data set comprehends a representative sample of 920 illegal

\footnotetext{
${ }^{1}$ In this paper we will interchangeably use the terms "undocumented", "illegal" and "irregular".

${ }^{2}$ See Tapinos (1999) and Jandl (2004) for an overview of the statistical approaches to measure irregular migration. See Hanson (2006) for a recent overview on the illegal migration between Mexico and the US.
} 
migrants who crossed the Italian borders in 2003 and were kept in host centers for identification, where they have been interviewed. One of the most important features of these data is that they contain information on the migrants' expectations "at the gate" concerning their intentions to return and many other characteristics (e.g. intentions to remit, expectations on future income, employment, legal status, characteristics of the village of origin etc.). Indeed, by using this data set we are able to quantify the effects of skills and education on the return intention and at the same time to control for other relevant individual covariates.

Empirical results confirm the main findings of our proposition and, in particular, they highlight the importance of individual skills and the presence of migrants' networks in affecting the intention to return of illegal migrants.

To the best of our knowledge, this is the first contribution towards increasing our knowledge on the relationship between skill characteristics and return attitudes of illegal migrants, whose numbers far outpace those of legal migrants.

Indeed, regarding the relationship between skills and return intentions, most literature has focused on legal migrants. Many studies have emphasized that migrants are not randomly selected but generally represent the upper tail of the skills distribution of the population in the countries of origin (see Borjas et al., 1992, and Chiswick, 1999). Since migration is a particularly costly investment, only the most capable, entrepreneurial and risk-prone individuals usually undertake such an investment. The existing empirical research almost unanimously concludes that return migration is more likely for individuals with low skills and reinforces the positive self-selection of the migrants (Borjas et al. 1996; Dustmann 1993, 2003a, 2003b; Reagan and Olsen, 2000).

A similar study to ours on undocumented Mexican immigrants to the US is due to Orrenius and Zavodny (2005), who used the data of the Mexican Migration Project. Their analysis focuses on the first migration choice - i.e. the decision to leave the home country for the first time - and investigates the impact of migration determinants (especially the wage level in the origin country, Mexico, and in the destination country, US) on the skill composition of undocumented migration flows. Our paper can be considered a complementary study to theirs as dealing with return migration, although on a different data set in Europe.

The paper is organized as follows. Section 2 describes the main characteristics of the data set on Italian undocumented immigrants. Section 3 presents a theoretical (life-cycle) framework to model the return plans of irregular migrants with heterogeneous levels of skills. Section 4 reports and discusses the results of the empirical analysis. Lastly, Section 5 concludes with some general remarks and suggestions for further research. 


\section{Irregular Migration: description of the data}

The phenomenon of international migration seems to have undertaken relevant changes in the latter decades, especially in Europe. The flows of legal and documented migrants have been accompanied by a surge in irregular migrants. This can be related to the restrictive changes in migration policies occurred in most OECD countries since the mid-1970s (see Zimmermann, 1995, Faini, de Melo and Zimmermann, 1999, Venturini, 2003).

More precisely, the definition of irregular immigrant is strictly related to three characteristics of the international movement of people and labor force: the type of entry, the status of residence, the kind of work permit (see Tapinos, 1999). For instance, an alien that has legally entered the host country and has acquired legal residence, but no work permit, is considered an irregular migrant if she works. ${ }^{3}$

In 2003 the Department of Economics at the University of Bari has conducted a field survey - SIMI, Survey of Illegal Migration in Italy - by focusing on some specific types of illegal immigrants. Referring to the definition above, the survey was directed on migrants that failed all three legal requirements (entry, residence and work permit). In particular, the survey took advantage of the Italian law that prescribed apprehended undocumented aliens to be hosted in special residence centers (Centers of Temporary Residence or Centri di Permanenza Temporanea) to ascertain their identification. According to the law, this stay could be extended up to thirty days when there were no bilateral agreements with the country of origin to allow quick repatriation.

The field survey was mainly conducted in the host temporary centers, although some migrants were also interviewed at other aggregation places (public canteens, help and reception centers). The data were collected by means of questionnaires filled up by each individual with the help of an interviewer (usually a cultural mediator trusted by the migrants and previously trained on the questionnaire). ${ }^{4}$

The survey aimed at collecting individual data on "illegal immigrants", more specifically their main demographic and socio-economic characteristics, as well as

\footnotetext{
${ }^{3}$ There is a major difference between countries more immigration-prone - like the US and Canada - and more closed countries - like the European Union after 1970s. In the former ones the visa system is very stratified and allows a more clear identification of the three layers (entry, residence and employment). This has a consequence also on the type of illegal immigration. For instance, the common situation of a migrant that overstays his legal visit (and residence) in the US while waiting for a legal work permit has no counterpart in Europe, except for the rare cases of amnesties, since the issue of work permits (i.e. the legalization of employment, differently from entry and residence) is not clearly regulated. Then, the different attitudes towards legal migration have consequences also on the type of illegal migration, being less socially compatible in the closed countries rather than in the immigration-prone countries.

${ }^{4}$ For further details on the field survey see Chiuri, De Arcangelis, D'Uggento and Ferri (2004); for the statistical and methodological issues related to sampling see Chiuri and D'Uggento (2004).
} 
their motivations and future expectations from the (at least temporarily aborted) migration project.

To be more precise, by "illegal immigrant" (i.e. the sampling unit) SIMI defines a (at least 18-year old) clandestine or asylum seeker that has been in Italy for a period no longer than 6 months. ${ }^{5}$ This short period minimizes the measurement error when interviewees were asked to recall previous events. One of the aims of the survey was to obtain an accurate recollection of earnings and expenditures before migration, as well as future expectations before departure.

The sample included 920 individuals that were interviewed in the period JanuarySeptember 2003 in four border Italian regions (mainly concerned with the phenomenon of illegal entrance). ${ }^{6}$ The total number of individuals interviewed represented $10.82 \%$ of all the 8,502 illegal migrants that were hosted in the selected centers in the same period January-September 2003.

55 different nationalities have been represented in the sample; the six largest fractions were coming from: Iraq (9.6\%), Liberia (9\%), Sudan (5.4\%), Morocco (5.1\%), Senegal (4.8\%), Turkey (4.8\%).

Table 1 summarizes the characteristics of the sample that are more relevant for the present paper.

According to our data, the average illegal migrant entering Italy is young (about 27 years old). The declared family monthly income in the country of origin was on average around US\$218 (while average individual monthly income was US\$145), with a very high variability due to the extreme heterogeneity of the socio-economic conditions of the interviewees. It is noteworthy that interviewees, once settled down in the country of final destination, expected to earn an average monthly wage of US\$ 877.

Migration is a major investment for the family: on average the cost of the trip is equivalent to approximately 2 years of individual earnings in the country of origin.

Individuals in the sample can be classified in four sub-groups: clandestine immigrants (about one third of the sample), asylum seekers, individuals waiting for a rejection decree and individuals waiting for an expulsion decree (see Appendix B). Given the blurred definition of the latter two categories, in our analysis we only focus on clandestine migrants and asylum seekers.

Illegal immigrants into SIMI have a non-negligible level of skills that we measure in three different ways. First, the degree of illiteracy is not very high since only $13.2 \%$ declared they cannot read and write. In terms of schooling, $5 \%$ of the migrants in the sample have a University degree while $13.9 \%$ and $7.9 \%$ have respectively a secondary education degree and vocational education. Only $15.3 \%$

\footnotetext{
${ }^{5}$ See Appendix B for a thorough definition.

${ }^{6}$ The four regions are: Apulia, Calabria, Friuli Venezia Giulia and Sicily.
} 
Table 1: Main Characteristics of SIMI 2003, Survey on Illegal Migration in Italy (standard errors in parentheses).

\begin{tabular}{|c|c|c|}
\hline \multicolumn{3}{|l|}{ General } \\
\hline Number of sample units & 920 & \\
\hline Median Age (in years) & 27.2 & $(6.19)$ \\
\hline Family income at home (median, in US\$) & 851 & $(1,049)$ \\
\hline Expected income at destination (median, in US\$) & 3,676 & $(4,153)$ \\
\hline Number of children per head (mean) & 0.57 & $(1.09)$ \\
\hline children left home per head (mean) & 0.45 & $(0.95)$ \\
\hline Cost of the trip (median, in US\$) & 1,645 & $(1,417)$ \\
\hline Intention to return home & $58.9 \%$ & \\
\hline Intended length of stay (in years) & 3.9 & $(1.3)$ \\
\hline \multicolumn{3}{|l|}{ Sample composition } \\
\hline Clandestines & $29.8 \%$ & \\
\hline Asylum Seekers & $58.1 \%$ & \\
\hline Others & $12.1 \%$ & \\
\hline \multicolumn{3}{|l|}{ Skill characteristics } \\
\hline Illiteracy & $13.2 \%$ & \\
\hline \multicolumn{3}{|l|}{ School degree } \\
\hline primary & $27.1 \%$ & \\
\hline middle & $30.8 \%$ & \\
\hline high-school & $21.7 \%$ & \\
\hline university & $5.0 \%$ & \\
\hline Good host-country language proficiency ${ }^{a}$ & $20.2 \%$ & \\
\hline Basic host-country language proficiency & $26.6 \%$ & \\
\hline \multicolumn{3}{|l|}{ Job qualification ${ }^{\mathrm{b}}$} \\
\hline low-skilled & $76.5 \%$ & \\
\hline high-skilled & $18.3 \%$ & \\
\hline \multicolumn{3}{|l|}{ Migration network } \\
\hline Number of relatives (people cohabiting) & & \\
\hline already in the final destination per head & 0.19 & 0.39 \\
\hline
\end{tabular}

a Percentage of migrants with declared good proficiency ("basic" level through "very good" level) in the language of the intended destination country.

b High-skilled qualification is considered for the following (declared) jobs before migration: translator, secretary, financial advisor, doctor or chemist, lawyer, teacher, manager, consultant, entrepreneur. 
of the sample declares to have no formal education. Other two indirect measures of skills are represented by the degree of host-country language proficiency and by the type of declared job qualification. Over a quarter of the migrants has a basic knowledge of the destination country's language and another $20 \%$ of the migrants declare to have a good knowledge of it. A significative share of the migrants $(18.2 \%)$ can be classified as high-skilled on the basis of the job qualifications in the country of origin, although the majority of the migrants are low-skilled. Only $18 \%$ of the individuals within our sample migrate within a network of already established migrants (relative and friends) from the same community of origin. This is a distinctive and important feature of our data if compared to other surveys on illegal migrants (such as for example the Mexican Migration Project) which are by construction deeply unbalanced toward individuals who migrate within a network.

About $60 \%$ of the interviewees declared to have intentions to return home. In the following section we analyse the link between skills endowments and return decisions of illegal migrants in a very simple life-cycle framework.

\section{Skills and Return Decisions of Irregular Mi- grants: A Simple Life-Cycle Interpretation}

The main point of our paper is that the effect of illegality dampens the return on skills of immigrants; hence, it provides a higher incentive to return home to the highly skilled migrants rather than to the low-skilled ones.

It can be given a very simple life-cycle interpretation of this intuition. Let us consider a two-period discrete world where the utility function of the illegal migrant takes the usual logarithmic form:

$$
U=\ln \left(C_{1}\right)+\delta \ln \left(C_{2}\right)
$$

$C_{1}$ and $C_{2}$ are consumption in period 1 and period 2 respectively; $\delta$ is the subjective discount factor.

The illegal migrant has already reached the destination country $B$ and earns in period 1:

$$
w_{1}=a \tau w^{B}
$$

where $w^{B}$ is the average wage in the destination country $B ;^{7} a$ is the migrant skill

\footnotetext{
${ }^{7}$ We are not modelling at all the choice to leave the origin country and assume instead that the migrant has already arrived illegally in the country of destination. This choice is due to mimic closer the situation of the individuals in our sample described in Section 2, for whom the choice to leave is already done. Orrenius and Zavodny (2005) deals with the issue of whether to leave the origin country or not and reside illegally at destination.
} 
level and we assume that migrants' skills are continuously distributed over the interval $[\underline{a}, \bar{a}]$; finally, $\tau \in(0,1]$ captures the magnitude of the skill waste effect associated with the status of illegal migrant. As $\tau \rightarrow 0$ illegal migration tends to be less and less rewarding for all illegal migrants and has a squeezing effect on the level of human capital, i.e. being uneducated and unskilled rather than having a $\mathrm{PhD}$ in engineering does not change the returns from migration. ${ }^{8}$ On the contrary, when $\tau=1$ there is no skill waste and migrants' human capital is fully rewarded according to the skill content $a$.

Income in period 2 depends on what the illegal immigrant decides at the end of period 1, whether to go back home to country $A$ or to stay in the destination country $B$ where there is a nonzero probability of becoming legal.

In case of return, in period 2 the migrant will be able to be fully rewarded for his/her skills and no illegality skill-waste effect takes place, but in the origin country $A$ the average wage $w^{A}$ is lower than in the destination country. Summarizing, the period- 2 wage in case of return is given by:

$$
w_{2}^{R}=a w^{A}
$$

If the illegal migrant decides to stay in the country $B$, she will face a probability $\gamma$ of getting legal status and therefore of fully exploiting her skills in the labor market. ${ }^{9}$ Hence, the expected wage for period 2 in case of no return is the following:

$$
w_{2}^{N R}=\gamma a w^{B}+(1-\gamma) a \tau w^{B}
$$

where $a w^{B}$ is the wage (without skill waste) that she would get in case she obtains a legal status (with probability $\gamma$ ) and $a \tau w^{B}$ is the wage that she will get in case that she does not get legal status (like in period 1).

We can rewrite more compactly the period-2 wage in case of no return as follows:

$$
w_{2}^{N R}=h a w^{B}
$$

\footnotetext{
${ }^{8}$ Even if $\tau=0$ is implausible since the brightest and more skilled migrants are more likely to obtain the best opportunities, skills and formal qualification are of little use to an illegal migrant. Very often migrants employed illegally in highly unskilled and manual jobs - such as agricultural workers in developed countries - are highly skilled and educated individuals.

${ }^{9}$ For simplicity and without loss of generality we assume that $\gamma$ does not depend upon skills. While this is probably true for Italy, we acknowledge that in several host countries, which have selective immigration policies, the probability of obtaining legal status might positively depend upon skills. A version of the present framework taking this aspect into consideration is available from the authors upon request. Intuitively, the effect of such an extension is straightforward (a reduction in the range of the parameters for which return is more likely for highly skilled illegal immigrants relative to the low-skilled ones) and does not affects the main insights of the proposition.
} 
where $h \equiv \gamma+(1-\gamma) \tau$.

One final important consideration regards the use of financial markets to carry savings from period 1 to period 2 . Let us define $R^{j} \equiv\left(1+r^{j}\right)$ as the rate of return for country $j$. We assume that the rate of return of the illegal migrant is affected by both skills and the illegal status. Indeed, many empirical studies have shown that the funds repatriated are likely to be employed in entrepreneurial activities whose rate of return will depend on individual abilities. ${ }^{10}$ In our model, at the end of period 1 if the migrant decides to return home, he/she will invest her savings in the origin country and obtain a rate of return equal to $a R^{A}$. We are implicitly assuming that at the end of period 1 the illegal migrant is repatriating her savings and that the rate of return obtained is proportional to her skills. In case of no return, the illegal migrant uses the destination country financial markets to invest her savings. Once again, the rate of return will depend on personal skills, that are influenced by illegality through the skill waste effect: $a \tau R^{B}$. In order to simplify the framework and allow for a simple graphical interpretation, we also assume that the "normal" rate of return is not different in the two countries, i.e. $R^{A}=R^{B}=R .^{11}$

Summarizing, the problem of the illegal migrant is to maximize her utility $U$ in (1) under two different budget constraints depending on whether returning to the home country $A$ or staying in the destination country $B$. In case of return the intertemporal budget constraint is given by:

$$
C_{1}+\frac{1}{a R} C_{2}=a \tau w^{B}+\frac{1}{a R} a w^{A} .
$$

Whereas, in case of no return:

$$
C_{1}+\frac{1}{a \tau R} C_{2}=a \tau w^{B}+\frac{1}{a \tau R} h a w^{B}
$$

In Figure 1 the continuous budget constraints are drawn under the assumption that neither return nor "no return" are revealed-preferred, i.e. that the two budget constraints intersect in the first quadrant. ${ }^{12}$

Moreover, since the budget lines change for different values of skills, we considered the special skill level $a^{*}$ for which utility in case of return and "no return"

\footnotetext{
${ }^{10}$ See World Bank (2006) for a recent thorough study on the effect of remittances on development.

${ }^{11}$ See the Appendix A for a generalization of the model with two different rates of return.

${ }^{12}$ Since the slope of the "no return" $(N R)$ budget constraint is lower than in the case of return, then it suffices to show that the intercept the the NR budget constraint, i.e. $\bar{C}_{1}^{N R}$, is higher than the intercept of the budget constraint in case of return, i.e. $\bar{C}_{1}^{R}$. It is easy to show this happens when $\frac{w^{B}}{w^{A}}>\frac{\tau}{h}$. Hence, a sufficient condition is $w^{B}>w^{A}$, which is very plausible.
} 


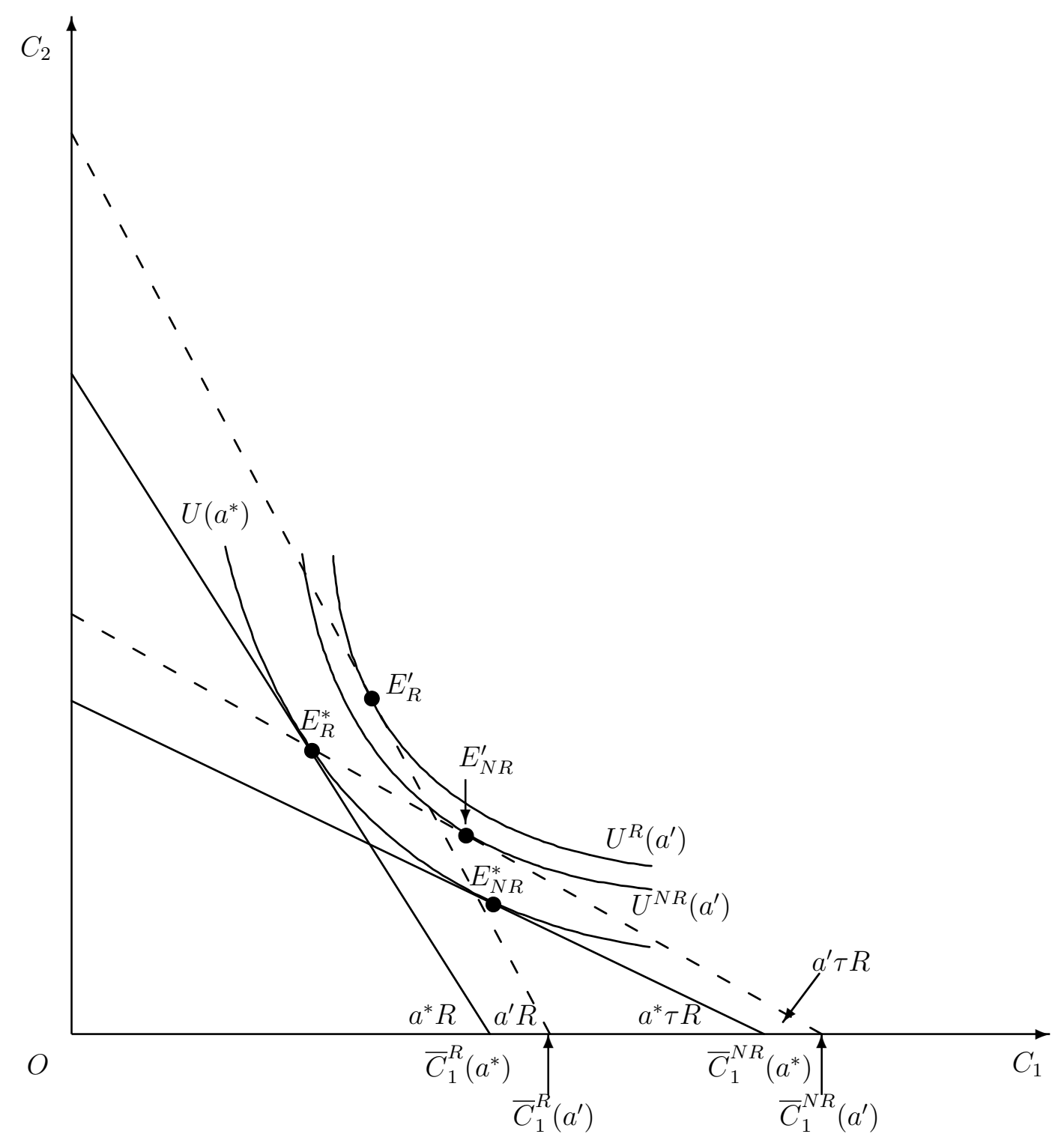

Figure 1: The welfare effect of skill variation in both cases of return and no return. 
is the same and equal to $U\left(a^{*}\right)$, as indicated by the indifference curve reported in the graph.

When we consider an individual with skill level $a^{\prime}>a^{*}$, the new budget constraints will tilt and move outwards, as shown in the Figure 1 by the dashed lines. The movement outwards is due to the increase in life-cycle income, whereas the tilting is caused by the fact that the rates of return depend on the individual skill level. However, since in case of "no return" the rate of return is reduced by the skill waste effect, the tilting will be lower.

It can be formally shown that the new intertemporal bundles $E_{R}^{\prime}$ and $E_{N R}^{\prime}$ will not lay on the same indifference curves and the return option will be chosen since it assures a higher welfare. ${ }^{13}$

In both cases of return and "no return" the increase in the skill level induces both a substitution and an income effect. Whether or not the individual decides to go back home, the latter effect is the same, as also shown by the shift of the intercepts from $\bar{C}^{R}\left(a^{*}\right)$ to $\bar{C}^{R}\left(a^{\prime}\right)$ and from $\bar{C}^{N R}\left(a^{*}\right)$ to $\bar{C}^{N R}\left(a^{\prime}\right)$. Instead, the substitution effect is higher in case of return because of the (absence of the) skill waste effect. In the next section we test the implication of the life-cycle approach by means of the data from SIMI.

\section{Empirical Investigation}

\subsection{Model specification}

Our simple model suggests that the level of skills (parameter a) positively affects the return plans of the individuals who migrated illegally. In order to test this implication we specify a probit model for the intentions to return of irregular migrants (i.e. the dependent variable is equal to 1 if the individual has stated that he/she would return home, zero otherwise). Exact definitions and basic statistics of the explanatory variables are presented in Appendix C, as well as the relative data sources.

Our main task is to test whether individual skills affect the intention to return. We consider three different measures of individual skills and abilities: years of schooling, a dummy for highly skilled workers ${ }^{14}$ and a dummy for the individual high proficiency in the language of the intended country of destination. ${ }^{15}$ In accor-

\footnotetext{
${ }^{13}$ See the Appendix A for a formal proof.

${ }^{14}$ High-skilled qualification is considered for the following (declared) jobs before migration: translator, secretary, financial advisor, doctor or chemist, lawyer, teacher, manager, consultant, entrepreneur. See Appendix C for the thorough definition of high-skill and low-skill jobs.

${ }^{15}$ The dummy in equal to one when the declared language proficiency is "basic" level through "very good" level. See Appendix C for the thorough definition of "high proficiency".
} 
dance with Section 3, for the more skilled migrants the skill waste effect associated with illegality increases the opportunity cost of continuing to reside (illegally) in the destination country. Thus, we expect variables measuring high skills to have a positive effect on the probability of returning to the country of origin.

The intensity of the skill waste might be affected by the presence in the destination country of networks of already established migrants. In fact, the existence of migration networks has two opposite effects on return intentions:

(i) Higher expected returns from migration. Networks of already established migrants might provide both personal support and more accurate information on the destination country and therefore affect positively the expectation of obtaining a good job (see for instance Munshi, 2003). This would have a negative effect on return decision.

(ii) Increase in temporary migration. The existence of networks might reduce the perception of risks associated with the migration experience. This safety net provided by established migrants might lead some individuals (in particular the 'target-savers migrants'), who are highly risk-adverse or highly attached to the home country, to migrate temporarily. This effect will naturally increase the number of individuals that migrate but only temporarily and therefore the overall likelihood of return in the migrant community.

The overall effect of network on return decision will depend on the relative strength of the above effects. In addition, as already mentioned, the effect (i) might also be influenced by the migrant skills level: the presence of migrants' networks would mitigate the intensity of the skill waste. Hence, the positive network externality, which reduces the probability of return, is relatively higher for the most skilled migrants.

In order to capture these effects, we include a dummy for the declared presence of a migration network at destination (Migronetwork) ${ }^{16}$ and an interaction effect between this variable and the three measures of skills. Whereas the former can take both signs depending on the relative strength of the above-mentioned effects, we expect the latter to have a negative effect on the probability of return.

Besides the measures of skills and the interaction with the presence of social networks, intentions to return depend on many other variables. We collect them into two main sets: pure "individual's covariates", which refer to the personal migrant's situation, and "country-level variables", which refer to the characteristics of the country of origin of the individual migrant.

\footnotetext{
${ }^{16}$ This is measured by the "Number of relatives (people cohabiting) already in the final destination" reported by each individual.
} 
- Individual's covariates. Let us recall that the decision of whether to return or not depends on future individual opportunities in the country of origin. These are influenced by previous job experiences at home. Thus, we include a dummy variable for being unemployed in the home country before migrating, which is expected to have a negative influence on the probability of returning.

We also introduce a few individual variables that control for other factors that might affect the choice of returning. In fact, together with business and entrepreneurial motivations, one might decide to return because of family and cultural ties (see Dustmann, 2003a). ${ }^{17}$ We therefore include two proxies that give a measure of the intensity of family ties: number of children left at home, as a proxy of close family ties, number of relatives left at home for extended family ties. These are both expected to have a positive effect on the return choice.

Moreover, since previous migration experience generally lowers the nonmonetary and psychological costs of subsequent migrations, we added the dummy variable Previous Migration for individuals that had such an experience in our sample. The expected sign is negative on the return choice.

Finally, we include a dummy of value one for being clandestine in order to isolate the probable effect of belonging to either one of the categories of illegal migrants included in our sample, i.e. asylum seekers or pure clandestine migrants. Asylum seekers are motivated to notify their presence to the authorities of the receiving country, whereas clandestine immigrants shy away from official contacts and tend to live working quietly, waiting for the next amnesty to make them legal. The probability of being granted legal status, while positive for both categories of migrants, is generally higher for asylum seekers. Since being legal increases the ability of migrants to fully employ her human and financial capital in the country of destination, we expect the effect of the clandestine dummy to be positive on the probability to return.

- Characteristics of the country of origin. In these category we include both economic and social variables. It is widely acknowledged that return intentions are affected by the expected economic opportunities in the country of origin (i.e. the "normal" wage $w^{A}$ in Section 3). Return migration will be generally higher in countries that are at an intermediate level of development and would offer opportunities to migrants who have accumulated human and financial capital. Hence, we introduce a measure of the infrastructure endowment in the country of origin, which is expected to have a positive effect on return.

\footnotetext{
${ }^{17}$ More broadly these factors might also proxy for the psychic cost of migration and may be modeled as a fixed disutility flow for each period the migrant is far away from the family.
} 
Aside from the theoretical model, the peculiarity of the dataset allows us to distinguish the effects of social conflicts and that of financial or economic crises in the village/city of origin on the choice of return. ${ }^{18}$ They are included as dummy variables. These events might have different implications on the intentions to return. In fact, while social conflicts or civil wars may have a permanent effect on migration, economic or financial crises may lead to a temporary out-migration to be subsequently re-absorbed when economic conditions improve again.

Along a similar line of thinking, we control for the effects on return intentions of belonging to a minority group (either religious or ethnic) in the home country. Minority groups in many countries of origin represented in our sample suffer from discrimination and sometimes violent persecutions. Hence, in our analysis we include an interaction effect between a dummy variable minority (equal to one if the migrant belongs to a minority group in the country of origin) and an index of ethnic polarization, which aims to capture potential conflicts and the concentration of power "outside" the minority. This latter index ranges from 0 to 1 and polarization reaches a maximum when there are two religious/ethnic groups of equal size. ${ }^{19}$ As a matter of construction, this variable is expected to have a negative effect on the probability of return.

Moreover, we include the (log of) geographical distance as a proxy for the monetary and psychological cost of migration. When distance is short, migrants can afford frequent journeys back home; hence, the expected sign of this variable on the probability to return is positive.

Finally, other controls are included in the estimation. ${ }^{20}$ As far as cultural ties with the country of origin are concerned, it is widely accepted that the cost of residing in a foreign country increases with the degree of cultural and social diversity between the origin and destination countries. A different religion is an important dimension on which such diversities are expressed. Hence, we include a dummy variable, Muslim, that aims to capture the - generally greater - psychological cost of migration faced by individuals of Islamic religion, and this is supposed to have a positive effect on the return choice.

At last, we include macro-area dummies in order to capture the characteristics of the geographical areas of origin that are not observable. The limited number of

\footnotetext{
${ }^{18}$ In terms of the model, they may be related once more to the "normal" wage in the country of origin $w^{A}$, although the two variables will prove to have a different effect among each other.

${ }^{19}$ For recent analysis concerned with the effects of religious and ethnic polarization on economic development see Montalvo and Reynal-Querol (2003, 2004).

${ }^{20}$ They are listed here, but the estimates are not included in Table 2 for the economy of the presentation. They are available in the Appendix $\mathrm{C}$ as Table 4.
} 
observations, but the large number of countries in our dataset, do not allow us to use country dummies.

\subsection{Estimation Results}

Table 2 and 3 show the estimates and the relative marginal effects, respectively. Although we present the results of different specifications in what follows we only comment on the most completed one (Model 5). ${ }^{21}$

${ }^{21}$ Other specifications are also available from the authors upon request. 


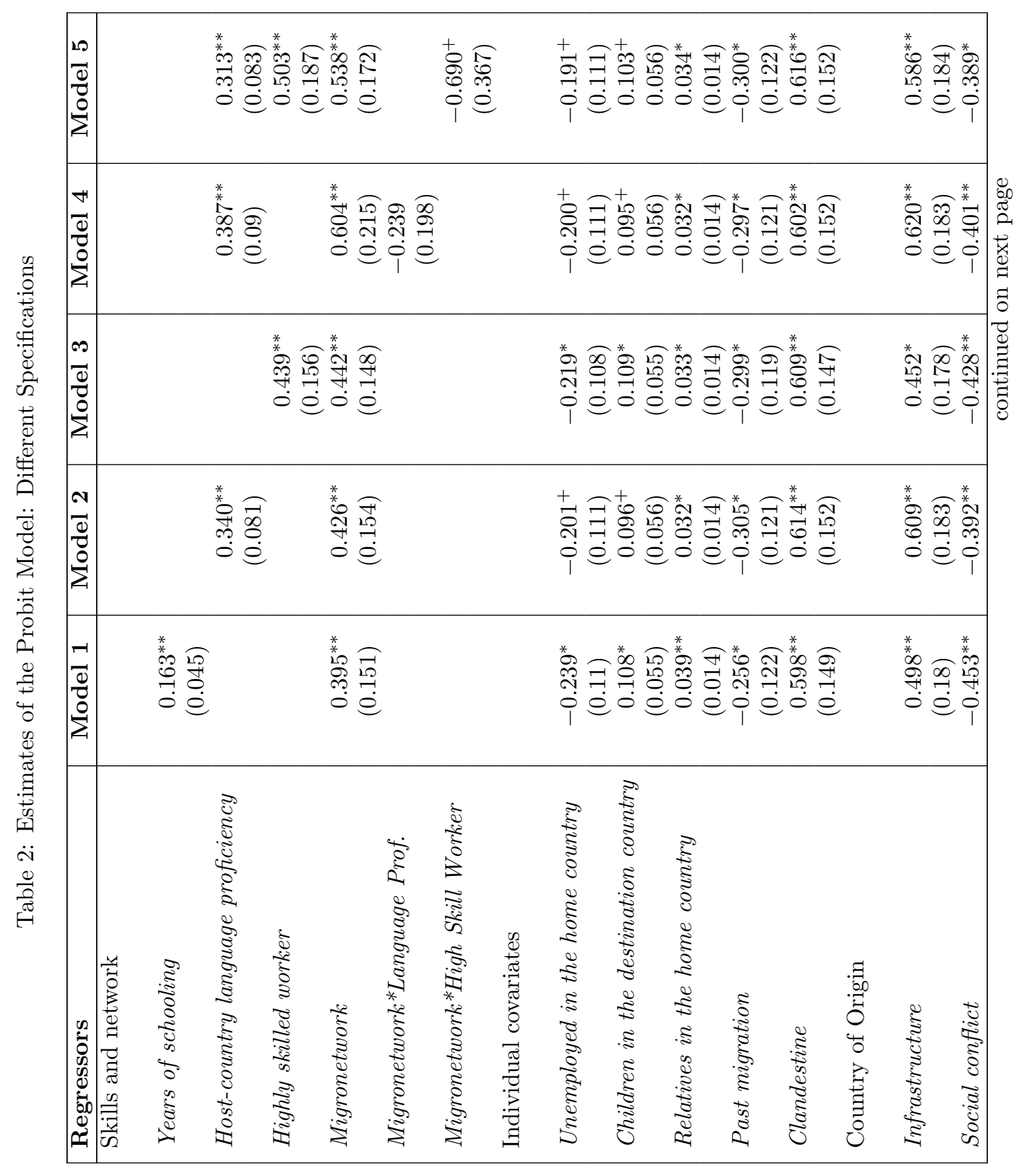




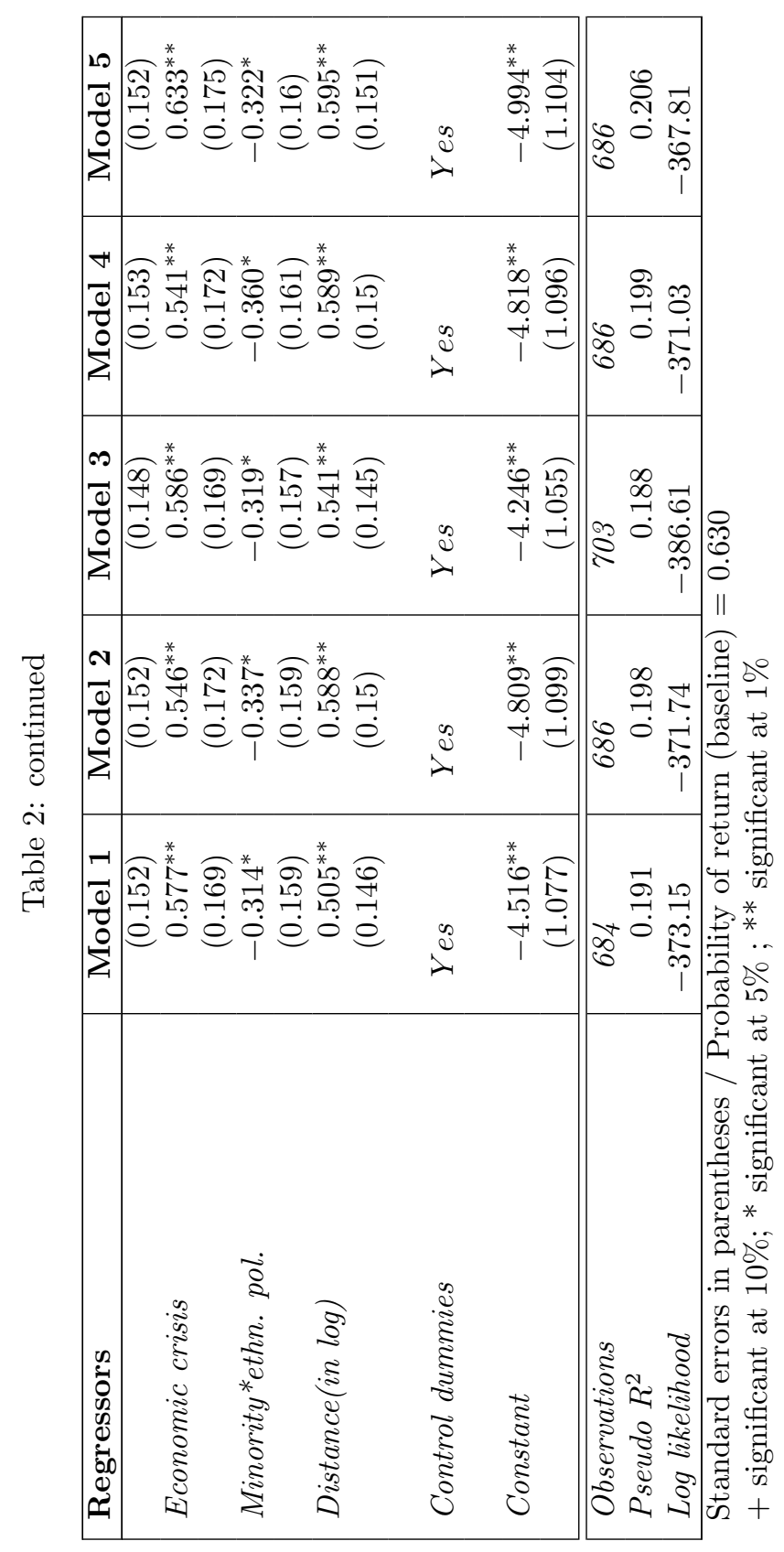


Table 3: Marginal Effects of Model (5)

\begin{tabular}{|c|c|}
\hline Regressors & Marg. Eff. \\
\hline Host-country language proficiency & $\begin{array}{c}0.118^{\text {** }} \\
(0.031)\end{array}$ \\
\hline Highly skilled worker & $\begin{array}{c}0.175^{* *} \\
(0.058)\end{array}$ \\
\hline Migronetwork & $\begin{array}{c}0.188^{* *} \\
(0.054)\end{array}$ \\
\hline Migronetwork*High Skill Worker & $\begin{array}{r}-0.270^{*} \\
(0.139)\end{array}$ \\
\hline Unemployed in the home country & $\begin{array}{c}-0.072^{+} \\
(0.042)\end{array}$ \\
\hline Children in the destination country & $\begin{array}{c}0.039^{+} \\
(0.021)\end{array}$ \\
\hline Relatives in the home country & $\begin{array}{c}0.013^{*} \\
(0.005)\end{array}$ \\
\hline Past migration & $\begin{array}{r}-0.115^{*} \\
(0.047)\end{array}$ \\
\hline Clandestine & $\begin{array}{c}0.220^{* *} \\
(0.050)\end{array}$ \\
\hline Infrastructure & $\begin{array}{c}0.199^{* *} \\
(0.054)\end{array}$ \\
\hline Social conflict & $\begin{array}{r}-0.141^{*} \\
(0.053)\end{array}$ \\
\hline Economic crisis & $\begin{array}{c}0.247^{* *} \\
(0.067)\end{array}$ \\
\hline Minority*ethnic polarization index & $\begin{array}{r}-0.122^{*} \\
(0.061)\end{array}$ \\
\hline Distance (in log) & $\begin{array}{c}0.225^{* *} \\
(0.057)\end{array}$ \\
\hline Observations & 686 \\
\hline
\end{tabular}

Probability of return (baseline) $=\mathbf{0 . 6 3 0}$

Note: for the dummy variables the marginal effect is referred to the change from 0 to 1 .

Standard errors in parentheses

+ significant at $10 \%$; ${ }^{*}$ significant at $5 \%$; ${ }^{*}$ significant at $1 \%$

Results are generally in line with our expectations. Skills and education significantly increase the probability of return to the home country. In order to check for rubustness of results, we present in Models $1-3$ alternative measures of skills which are all strongly significant. Although each measure captures a different dimension of individual skills and abilities, a significant correlation between years of schooling and highly skilled workers prevents us to jointly employ them. In Model 5 , we employ the latter since, given the high heterogeneity of educational systems in the countries covered by our sample, the variable highly skilled workers might be a more precise measure of individual abilities. 
We find that the knowledge of the language of the intended destination countries has a strong effect on intentions to return. An individual with a good knowledge of the language of the intended destination's country is $22.1 \%$ more likely to return than an individual with no knowledge of it. Indeed, the probability of return of a relatively skilled person, if he is not migrating within a network of established migrants, is $17.5 \%$ higher than the probability of return of an individual with no or low skills. On the contrary, highly skilled individuals migrating within a network seems to be, in line with existing evidence, less likely to return (9.5\%). This finding is consistent with the above mentioned positive role that networks might have in softening the skill waste effects. Note also that, although not significant at the common probability levels, the interaction effect between networks and host-country language proficiency (Model 4) shows a negative sign.

Most existing studies on return migration and return intentions of legal migrants highlight a generally lower propensity to return for highly skilled individuals. Those studies do not take into account the existence and the effects of migrants networks. Using data from the German Socio-Economic Panel, Dustmann (1996, $2003 \mathrm{~b}$ ) finds a negative effect of years of schooling on the intention to return to the home country. He also finds that for those who intend to return, schooling has a negative impact on the duration of the migration spell. This is explained by the fact that higher schooling, guaranteeing higher salary, reduces the time needed to achieve a pre-determined saving target. In a related study on the factors which affect the return migration of a cohort of foreign-born in the US, Reagan and Olsen (2000) find no evidence of skill bias in return migration. Our results seems to be consistent with Zhao (2002). In his analysis on rural to urban migration in China, Zhao finds that better educated and skilled rural migrants are more likely to return to their village of origin. The explanation offered by the author also fits our interpretation: both the strong segmentation in the urban labor market and the tight migration regulatory system in China prevent the full participation of skilled workers coming from rural area. This imposes heavy costs on skilled migrants in terms of rewards to education and work experience.

As expected the status of unemployed in the country of origin before departure negatively affects the intentions to return. Previous labor market performances, in fact, might be considered as a proxy for lack of opportunities at home.

In addition, we find evidence of the importance of family and cultural ties. In our estimations, an individual with two children left in the home country is 7.6 percentage points more likely to return than in the case where no children are left in the home country. Also the size of the family left in the country of origin significantly affect return intentions. Our evidence is in conformity with Dustmann (2003a) where the presence of children in the host country negatively affects the return intention of parents. It is widely ackwoledged that previous migrating 
experiences reduce the psychological cost of further moves. This is confirmed in our analysis as the dummy variable past migration experience is positive and highly significant. In accordance with our expectations clandestine are more likely to return in the home country.

Illegal migrants are also found to be more willing to return in countries that are relatively more developed. ${ }^{22}$ Countries that have an above average level of infrastructures (as measured by the dummy infrastructure) are $20 \%$ more likely to attract migrants back home.

Interestingly we also acknowledge that social conflicts and economic crisis have opposite effects on the return choice. The effect of having experienced an economic or financial crisis in the village of origin seems to be temporary whereas social conflicts have a more permanent effect on migration. ${ }^{23}$ Note also that migrants belonging to a religious or ethnic minority in the country of origin are less likely to return: the probability of remaining in the destination country is increasing in the degree of religious polarization, i.e. the higher is potential hostility faced by a religious minority in the country of origin.

Finally, the coefficients on the proxies for monetary and psychic cost of migration, namely distance and muslim, are significant and positive, respectively.

\section{Conclusions}

In this paper we assumed that the status of illegal migrant hinders the full utilization of individual skills. As a consequence, the opportunity cost of returning home is lower for highly skilled migrants rather than individuals with few or no skills. Interestingly, we find that the existence of a migrant network in the destination country might soften the negative consequences of illegality on the remuneration of individual's skills and abilities. In turn this might induce skilled workers to be more willing to stay in the destination country.

This result has been dealt with both theoretically and empirically. A simple two-period model with skill waste has shown that the return choice is more likely for individuals with more abilities. Empirical estimates of a probit model on the intentions to return home have been obtained on a sample of apprehended illegal immigrants hosted temporarily in Italian centers. The employed measure of individual skills (years of schooling, host-country language proficiency, level of skills on the job at home) affect the intentions to return home in the predicted direction. Other control variables prove the validity of the empirical model.

\footnotetext{
${ }^{22}$ Recalling Proposition 1 in the Appendix all illegal migrants will go back home when the wage gap is lower than the rate-of-return gap.

${ }^{23}$ We note this finding confirms the importance of a coordinated, timely and efficient international conflict prevention activity. See Chiuri, De Arcangelis and Ferri (2004)
} 
Since migration flows have proved to be unavoidable, the main message of this paper pinpoints the need to carefully design new immigration policies. In particular, it ought to be considered that a generic ban is not neutral and gives greater incentives to the more skilled workers to return home rather than to the low-skill migrants.

This latter consideration implies also to rethink the link between migration and development when illegal migration is particularly relevant. Our results show that skilled illegal migrants are more likely to return, but this does not imply that illegal migration alleviate the consequences of the brain drain from poor countries.

On the contrary, illegality reduces the economic dividend of migration for the country of origin not only because it keeps illegal migrants' wages low in the destination countries, but also because it reduces the incentive to acquire human capital, both before departure and during the migration experience. This latter effect undermines the fundamentals of the so-called "beneficial brain-drain hypothesis", according to which the possibility to migrate in a rich country might induce individuals to boost their investment in human capital already when they are in the country of origin (Mountford, 1997; Stark et al. 1997, 1998; Beine, Docquier and Rapoport, 2001). The possibility to migrate irregularly, together with the likely inability to fully employ human capital, might turn the "beneficial brain-drain hypothesis" on its head and further distort the incentive to accumulate human capital in poor countries. Illegality might indirectly contribute to keep poor countries locked in a poverty trap characterized by out-migration and low human capital accumulation.

\section{References}

[1] Beine M., , Docquier F. and H. Rapoport (2001), "Brain Drain and Economic Growth: Theory and Evidence", Journal of Development Economics, 64 (1): 275-89.

[2] Borjas G.J. and Bratsberg B. (1996), "Who leaves? The emigration of the foreign-born", Review of Economics and Statistics, Vol 78 (1), pp. 165-67.

[3] Borjas, G., Bronars S. G., Trejo S. J. (1992), "Self-Selection and internal migration in the United States", Journal of Urban Economics, 32: 159-185.

[4] Chiswick Barry R. (1999), "Are Immigrants Favorably Self-Selected?", American Economic Review, 89 (2), May 1999, pp. 181-185.

[5] Chiuri, M.C., G. De Arcangelis and G. Ferri (2004), "Crises in the Countries of Origin and Illegal Immigration into Italy", ChilD Working Paper n. 16/2004, (http://www.child-centre.it/papers/child16_2004.pdf). 
[6] Chiuri, M.C., G. De Arcangelis, A. D’Uggento and G. Ferri (2004), "Illegal Immigration into Italy: Results from a Recent Field Survey", CSEF Working Paper n. 121, (http://www.dise.unisa.it/WP/wp121.pdf).

[7] Chiuri M.C. and D'Uggento A.M. (2004) "Designing a survey on illegal migration in Italy: methodological issues and preliminary results", Paper presented at the Annual Meetings of the Italian Statistics Society, June 2004.

[8] De Melo J., Faini R. and Zimmermann K.F. (1999), Migration: The Controversies and the Evidence, Cambridge University Press, Cambridge (UK).

[9] Dustmann C. (1996), "Return migration: the European experience", Economic Policy, Vol. 22, pp. 214-250.

[10] Dustmann C. (1997), "Return Migration, uncertainty and precautionary savings", Journal of Development Economics, Vol. 52, pp. 295-316

[11] Dustmann C. (2003a), "Children and Return Migration", Journal of Population Economics Vol.16, pp. 815-830.

[12] Dustmann C. (2003b), "Return migration, wage differentials, and the optimal migration duration", European Economic Review, Vol. 47, pp. 353-369.

[13] Galor O., Stark O. (1990), "Migrants' savings, the probability of return migration and migrants' performance", International Economic Review, Vol. 31, pp. 463-467;

[14] Hanson, G. H. (2006), "Illegal Migration from Mexico to the US", mimeo, UC San Diego, forthcoming in Journal of Economic Literature.

[15] Jandl M. (2004), "The Estimation of Illegal Migration in Europe", Studi Emigrazione - Migration Studies, Vol. 51, pp 141-155.

[16] Montalvo J. G., Reynal-Querol M. (2003), "Religious polarization and economic development", Economics Letters, Vol. 80, pp. 201-210.

[17] Montalvo J.G., Reynal-Querol M. (2004), "Ethnic Diversity and Economic Development", Journal of Development Economics, Vol. 76, pp. 293-323.

[18] Mesnard A. (2004), "Temporary migration and capital market imperfections", Oxford Economic Papers, Vol. 56, pp. 242-262.

[19] Mountford A. (1997), "Can a Brain Drain be Good for the Growth in the Source Economy?", Journal of Development Economics, 53, pp. 287-303. 
[20] Munshi K. (2003), "Networks in the Modern Economy: Mexican Migrants in the U.S. Labor Market", Quarterly Journal of Economics, Vol. 118 (2), pp. 549-599.

[21] Orrenius P. M., Zavodny M. (2005), "Self-selection among undocumented immigrants from Mexico", Journal of Development Economics, Vol. 78, pp. 215-240.

[22] Reagan P.B. and Olsen R. J. (2000), "You Can Go Home Again: Evidence from Longitudinal Data", Demography, Vol. 37 (3), pp.339-350.

[23] Stark O. (1992), The Migration of Labor, Blackwell, Oxford.

[24] Stark O., Helmenstein C. and Prskawetz A. (1998), "Human capital depletion, human capital formation, and migration: a blessing or a 'curse'?", Economic Letters, 60, 363-367.

[25] Stark O., Helmenstein C. and Prskawetz A. (1997), "A Brain Gain with a Brain Drain", Economic Letters, 55, 227-234.

[26] Tapinos G. (1999), "Clandestine Immigration: Economic and Political Issues", Part III in SOPEMI, Trends in International Migration - 1999 Annual Report, OECD, pp.229-251.

[27] Venturini, A. (2003), Post-War Migration in South European Countries, Cambridge University Press.

[28] World Bank (2006), Global Economic Prospects 2006: Economic Implications of Remittances and Migration, Washington DC.

[29] Zhao Y. (2002), "Causes and Consequences of Return Migration: Recent Evidence from China", Journal of Comparative Economics, Vol. 30, pp. 376394.

[30] Zimmermann K.F. (1995), "Tackling the European Immigration Problem", Journal of Economic Perspectives, vol. 9, pp. 45-62. 


\section{APPENDIX}

\section{A The model}

Consider a population of illegal migrants with a heterogeneous level of skills from the same source country $A$ who have migrated to the host country $B$. Migrants' skills are continuously distributed over an interval $[\underline{a}, \bar{a}]$ where $\underline{a}$ and $\bar{a}$ represent respectively the individuals with the lowest and the highest skill level.

Individuals operate in a two-period world and are endowed with a unit of labor which is inelastically supplied in each of the two periods. ${ }^{24}$

The migrants' intertemporal utility function is defined over first- and secondperiod consumption and takes the following simple form:

$$
U\left(c_{1}, c_{2}\right)=u\left(c_{1}\right)+\delta u\left(c_{2}\right)=\ln \left(c_{1}\right)+\delta \ln \left(c_{2}\right)
$$

where $\delta$ is the discount factor.

In the first period individuals live and work in the host country $B$. Consumption of migrant $j$ is:

$$
c_{1}^{j}=w_{1}^{j}-s^{j}
$$

where $w_{1}^{j}$ is the first-period wage when working illegally in country $B$ and $s^{j}$ are savings.

Given their status of illegal migrants in the host country $B$ the rewards to human capital cannot be fully exploited: income earned in country $B$ is increasing in the skill level but we assume that the skill premium is compressed because of illegality. More precisely, first period wages are given by the following equation:

$$
w_{1}^{j}=a^{j} \tau w^{B}
$$

where $w^{B}$ is the exogenously given "normal" wage for a unit of labor in the host country.

Individual wages positively depend on individual skills but the status of illegal migrant makes those skills less effective. The parameter $\tau \in(0,1]$ captures the magnitude of the skill waste effect associated with the status of illegal migrant. As $\tau \rightarrow 0$ illegal migration tends to be less and less rewarding for all illegal migrants and has a squeezing effect on the level of human capital, i.e. being uneducated and unskilled rather than having a $\mathrm{PhD}$ in engineering does not change the returns from

\footnotetext{
${ }^{24}$ We assume that the individual possesses no capital at the beginning of the first period. In reality, it is often the case that migrants from less developed countries have a negative amount of wealth since they have borrowed from friends and relatives in order to pay for migration costs.
} 
migration. ${ }^{25}$ On the contrary, when $\tau=1$ there is no skill waste and migrants' human capital is fully rewarded according to the skill content $a^{j} \cdot{ }^{26} \mathrm{In}$ other words, when $\tau=1$ we assume that migration is legalized.

The parameter $\tau$ might be interpreted as the effect of the institutional framework within which illegal migration takes place on the individual's ability to use the stock of human capital accumulated at home. The degree to which it is possible for the migrant to exploit his or her skills might depend, for instance, on the attitude of the immigration authorities in the host country. When some particular skills are required due to an excess demand in the host country labor market, immigration authorities tend to be more tolerant toward illegal migrants possessing those skills (in this case $\tau$ may be close to 1 ).

In the second period migrants face two options. They can return to the home country $A$, where the exogenously given "normal" wage is $w^{A}\left(<w^{B}\right)$. In this case they fully use their skills and earn $a^{j} w^{A}$. Alternatively, they continue to reside in the host country $B$ where they face a positive probability of becoming legal migrants and therefore fully exploit their human capital.

The skill waste affects also the ability of illegal migrants to fully exploit financial markets in the host country and therefore the return on savings, which differs depending on the migrant's choice for the second period.

Often the sole motive for migration is the necessity to accumulate assets that will be subsequently employed in productive activities at home. Here we assume that if the migrant decides to go back to homeland $A$ in period 2 , then period-1 savings will be directly used, together with individual skills, in an entrepreneurial project with gross return $a^{j} R^{A}$ in the home country $A$ - where $R^{A}$ is the exogenously given "normal" gross return on savings in the home country. We allow for returns from the entrepreneurial project to differ between migrants. The higher the level of skills of the migrant, the higher the likelihood that she will locate

\footnotetext{
${ }^{25}$ Even if $\tau=0$ is implausible since the brightest and more skilled migrants are more likely to obtain the best opportunities, skills and formal qualification are of little use if you are an illegal migrant. Very often migrants employed illegally in highly unskilled and manual jobs - such as agricultural workers in developed countries - are highly skilled and educated individuals.

${ }^{26}$ Since all individuals found it profitable to migrate at the beginning of the first period and given that we abstract from differences in preferences for the location of consumption (associated for instance with relatively high preferences for home consumption) for any $a^{j} \in[\underline{a}, \bar{a}]$ the following inequality is satisfied:

$$
\tau a^{j} w^{B} \geq a^{j} w^{A} \Longrightarrow \tau w^{B}-w^{A} \geq 0
$$

where $w^{A}\left(<w^{B}\right)$ is the exogenously given "normal" wage for a unit of labor in the home country. In other words wage differentials more that compensate for the "skill waste" effect. Moreover, since we assume that illegal migrants have already chosen to live and work in the host country $B$ in period 1, the condition above imposes either a lower bound to the percentage wage gap $\widehat{w} \equiv \frac{w^{B}}{w^{A}}$ (i.e. $\widehat{w}>\frac{1}{\tau}$ ) or, given $w^{A}$ and $w^{B}$, a lower bound to $\tau$ (i.e. $\tau>\frac{w^{A}}{w^{B}}$ ).
} 
the best investment opportunities and, in turn, the more rewarding will be the allocation of her capital.

Similarly, savings are located in the host country $B$ in case the migrant decides to stay in $B$ during period 2 . The exogenously given "normal" return on savings in $B$ is $R^{B}$. Then, in case of a period-2 stay in country $B$, savings generate a return $\tau a^{j} R^{B}$, which is higher for individuals with higher skills, but is affected by the skill waste.

Hence, the return from savings will vary according to the migrant's location choice for the second period:

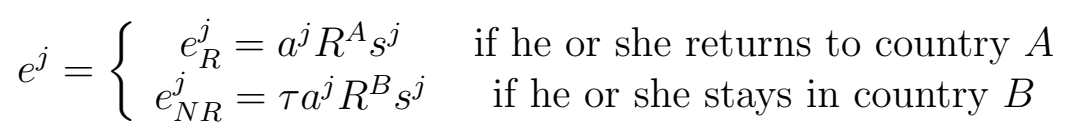

In other words, illegal migrants face constraints which negatively affect not only their ability to fully exploit their labor potential but also their ability to locate and exploit investment opportunities. For instance, although fully aware of the different financial opportunities offered in the host country, the illegal migrant does not have access to them since she does not have a legal permit and must recur to alternative, less rewarding and sometimes illegal, forms of financial investment. Instead, when planning to go back to the homeland, migrants immediately send home their savings, where they start their entrepreneurial project even before returning.

Therefore, consumption in second period also differs depending on the migrant's second-period choice. In case of return migration, consumption is given by:

$$
c_{2, R}^{j}=w_{2, R}^{j}+e_{R}^{j}=a^{j} w^{A}+a^{j} R^{A} s^{j}=a^{j}\left(w^{A}+R^{A} s^{j}\right)
$$

where in the home country return migrants are fully able to exploit their human capital as related to both their endowment of labor and the capital saved in the host country.

If migrants decide to stay in the host country they face a positive probability of getting legal residence. For instance, this might happen in the case of an amnesty granted to all illegal migrants who have being residing and working for a certain period in the host country or in the case of acceptance of an asylum application. The main consequence of being granted legal status in terms of our model is the ability to fully make use of individual skills, i.e. the skill waste effect disappears in the second period when the migrant obtains the legal status.

Consumption in this case can be expressed as the expected income in period $2\left(w_{2, N R}^{j} \equiv \widetilde{w^{j, B}}\right)$ plus the accumulated savings, invested in the host country $B$ $\left(e_{N R}^{j}\right)$ : 


$$
c_{2, N R}^{j}=w_{2, N R}^{j}+e_{N R}^{j}=\widetilde{w^{j, B}}+e_{N R}^{j}
$$

Given $\gamma$ as the probability of getting legal residence in period 2, then the expected wage for migrant $j$ in country $B$ in period $2\left(\widetilde{w^{j, B}}\right)$ will be: (i) $\tau a^{j} w^{B}$, i.e. the illegal immigrant's wage (the same as in period 1) in case of not getting legal status, with probability $(1-\gamma)$; (ii) $a^{j} w^{B}$, i.e. the legal immigrant's wage in case of getting legal residence, with probability $\gamma$.

Hence, the expected wage for period 2 in case of no-return is:

$$
\widetilde{w^{j, B}}=(1-\gamma) \tau a^{j} w^{B}+\gamma a^{j} w^{B}=a^{j} h w^{B}=a^{j} \widetilde{w^{B}}
$$

where $h \equiv[(1-\gamma) \tau+\gamma]$ and $\widetilde{w^{B}}$ is the expected "normal" period-2 wage in the host country $B$.

When substituting both expected income for period 2 and the return on saving into the expression (4) for consumption, it yields:

$$
c_{2, N R}^{j}=a^{j} h w^{B}+\tau a^{j} R^{B} s^{j}=a^{j} \widetilde{w^{B}}+\tau a^{j} R^{B} s^{j}
$$

Finally, the lifetime utilities functions of migrants depend on their decision whether or not to return. In the case of return:

$$
U_{R}^{j}\left(c_{1}, c_{2}\right)=\ln \left[\tau a^{j} w^{B}-s^{j}\right]+\delta \ln \left[a^{j}\left(w^{A}+R^{A} s^{j}\right)\right]
$$

Whereas in the case of no return:

$$
U_{N R}^{j}\left(c_{1}, c_{2}\right)=\ln \left[\tau a^{j} w^{B}-s^{j}\right]+\delta \ln \left[a^{j}\left(\widetilde{w^{B}}+\tau R^{B} s^{j}\right)\right]
$$

\section{A.1 Optimal Savings, Return Decisions and Skills}

The optimal level of savings $s^{* j}$ for an individual with skills $j$ is conditional on her location decision for the second period.

In the case of return migration the level of savings which maximizes the individual's intertemporal utility function (5), is given by:

$$
s_{R}^{j, *}=\frac{1}{R^{A}(1+\delta)}\left[\delta R^{A} w_{1}^{j}-w^{A}\right]=\frac{1}{R^{A}(1+\delta)}\left[\delta \tau a^{j} R^{A} w^{B}-w^{A}\right]
$$

If the illegal migrant decides to stay in the host country, then the optimal firstperiod savings will be determined by the maximization of the utility function (6). Hence, the optimal savings in case of no return is the following:

$$
s_{N R}^{j, *}=\frac{1}{\tau R^{B}(1+\delta)}\left[\delta \tau R^{B} w_{1}^{j}-\widetilde{w^{B}}\right]=\frac{w^{B}}{\tau R^{B}(1+\delta)}\left[\delta \tau^{2} a^{j} R^{B}-h\right]
$$


since $\widetilde{w^{B}} \equiv h w^{B}$ and $h \equiv[(1-\gamma) \tau+\gamma]$.

It is easy to show that savings in case of return are higher than saving in case of no-return when the percentage wage gap between the host country $B$ and the origin country $A$ - that is $\widehat{w} \equiv \frac{w^{B}}{w^{A}}$ - is higher than the percentage rate-of-return gap - that is $\widehat{R} \equiv \frac{R^{B}}{R^{A}}$ - i.e. when $\widehat{w}>\widehat{R}^{27}$

Several authors have emphasized that a positive probability of return induces migrants to save and remit more (see Galor and Stark, 1990; Stark, 1992; Mesnard, 2004). This result is in accordance with the life-cycle theory of consumption since individuals who plan to re-emigrate in a relatively poor country will save more in order to smooth their consumption path over the life-cycle. ${ }^{28}$

By substituting the optimal level of savings (7) and (8) in the respective utility functions (5) and (6), we obtain the indirect utility in case of return $\left(U_{R}^{j, *}\right)$ :

$$
\begin{gathered}
U_{R}^{j, *}\left(\delta, \tau, a^{j}, w^{A}, w^{B}, R^{A}\right)=(1+\delta) \ln \left[\frac{1}{1+\delta}\left(R^{A} \tau a^{j} w^{B}+w^{A}\right)\right]- \\
-\ln \left(R^{A}\right)+\delta \ln \left(\delta a^{j}\right)
\end{gathered}
$$

and in case of no-return $\left(U_{N R}^{j, *}\right)$ :

$$
\begin{gathered}
U_{N R}^{j, *}\left(\delta, \tau, a^{j}, w^{B}, R^{B}\right)=(1+\delta) \ln \left[\frac{w^{B}}{1+\delta}\left(R^{B} \tau^{2} a^{j}+h\right)\right]- \\
-\ln \left(\tau R^{B}\right)+\delta \ln \left(\delta a^{j}\right)
\end{gathered}
$$

Let us define the net indirect utility derived from returning $U^{j, *}$ for an illegal migrant with $j$ level of skills as the difference between the two optimal levels of utility. Hence:

$$
\begin{gathered}
U^{j, *}\left(\delta, \tau, a^{j}, w^{A}, w^{B}, R^{A}, R^{B}\right) \equiv U_{R}^{j, *}-U_{N R}^{j, *} \equiv \\
\equiv(1+\delta) \ln \left[\frac{R^{A} \tau a^{j} w^{B}+w^{A}}{\tau R^{B} \tau a^{j} w^{B}+h w^{B}}\right]-\ln \frac{R^{A}}{\tau R^{B}}
\end{gathered}
$$

which can be rewritten as:

${ }^{27}$ More precisely, $s_{R}^{j, *}>s_{N R}^{j, *}$ when:

$$
\frac{\widehat{w}}{\widehat{R}}>\frac{\tau}{[(1-\gamma) \tau+\gamma]}
$$

Note that the fraction $\frac{\tau}{[(1-\gamma) \tau+\gamma]}$ is always lower than 1 since $\tau \in(0,1]$.

${ }^{28}$ Higher incentives to save could also be motivated by a higher marginal utility of consumption in the home country, for instance due to higher purchasing power in the home country or strong preferences for home varieties or by the necessity to overcome higher uncertainty (see Dustmann 1997). 


$$
U^{j, *} \equiv(1+\delta) \ln \left[\frac{R^{A} w_{1}^{j}+w^{A}}{\tau R^{B} w_{1}^{j}+\widetilde{w^{B}}}\right]-\ln \frac{R^{A}}{\tau R^{B}}
$$

The discrete choice whether or not to return depends on the sign of the unobservable net utility $U^{j, *}$, which is determined in the following Propositions 1 and 2 .

Proposition 1 (Sufficient conditions for all migrants to stay in the host country $B$ ) No migrant decides to return, i.e. $U^{j, *}<0$, if:

(i) the "normal" (percentage) wage gap $\widehat{w} \equiv \frac{w^{B}}{w^{A}}$ is strictly higher than the "normal" (percentage) rate-of-return gap $\widehat{R} \equiv \frac{R^{B}}{R^{A}}$ :

$$
\frac{\widehat{w}}{\widehat{R}} \equiv \frac{\frac{w^{B}}{w^{A}}}{\frac{R^{B}}{R^{A}}}>1
$$

(ii) both the "normal" wage and the "normal" rate of return are strictly higher in the host country rather than in the home country, i.e.

$$
\tau w^{B}>w^{A} \quad \tau R^{B}>R^{A}
$$

Proof. Let us rewrite the net utility in eq. (11) as follows:

$$
U^{j, *} \equiv \ln \left[\frac{R^{A} w_{1}+w^{A}}{\tau R^{B} w_{1}+\widetilde{w^{B}}} \frac{\tau R^{B}}{R^{A}}\right]+\delta \ln \left[\frac{R^{A} w_{1}+w^{A}}{\tau R^{B} w_{1}+\widetilde{w^{B}}}\right]
$$

or

$$
U^{j, *} \equiv \underbrace{\ln \left[\frac{\tau R^{B} R^{A} w_{1}+\tau R^{B} w^{A}}{\tau R^{B} R^{A} w_{1}+R^{A} \widetilde{w^{B}}}\right]}_{[1]}+\underbrace{\delta \ln \left[\frac{R^{A} w_{1}+w^{A}}{\tau R^{B} w_{1}+\widetilde{w^{B}}}\right]}_{[2]}
$$

The first term [1] is negative if (and only if):

$$
\tau R^{B} R^{A} w_{1}+\tau R^{B} w^{A}<\tau R^{B} R^{A} w_{1}+R^{A} \widetilde{w^{B}}
$$

or

$$
\frac{R^{A} h w^{B}}{\tau R^{B} w^{A}}>1
$$

which can be written in terms of wage gap and rate-of-return gap: 


$$
\frac{\widehat{w}}{\widehat{R}} \equiv \frac{\frac{w^{B}}{w^{A}}}{\frac{R^{B}}{R^{A}}}>\frac{\tau}{h}
$$

Let us recall that $h \equiv[(1-\gamma) \tau+\gamma]$; hence, the fraction $\frac{\tau}{h}$ is certainly lower than 1 and the term [1] is always negative if

$$
\frac{\widehat{w}}{\widehat{R}}>1
$$

The second term [2] is negative when:

$$
R^{A} w_{1}+w^{A}<\tau R^{B} w_{1}+\widetilde{w^{B}}
$$

or

$$
R^{A} \tau a^{j} w^{B}+w^{A}<\tau R^{B} \tau a^{j} w^{B}+h w^{B}
$$

Let us rewrite the previous condition by employing the wage gap $\widehat{w}$ and the rate-of-return gap $\widehat{R}$ :

$$
R^{A} \widehat{w} \tau a^{j} \underbrace{(\tau \widehat{R}-1)}_{[\mathcal{A}]}>\underbrace{(1-h \widehat{w})}_{[\mathcal{B}]}
$$

A sufficient condition for $(15)$ is that the term $[\mathcal{A}]$ is positive and the term $[\mathcal{B}]$ is negative.

This occurs when:

$$
\tau \widehat{R}>0 \quad \Rightarrow \quad \widehat{R}>\frac{1}{\tau} \quad \Rightarrow \quad \tau R^{B}>R^{A}
$$

for term $[\mathcal{A}]$; and:

$$
h \widehat{w}>1 \quad \Rightarrow \quad \widehat{w}>\frac{1}{h}
$$

for term $[\mathcal{B}]$.

Since $\frac{1}{h}<\frac{1}{\tau}$, but condition (14) must be satisfied for term [1] to be negative, then a sufficient condition on $\widehat{w}$ would be:

$$
\widehat{w}>\frac{1}{\tau} \quad \Rightarrow \quad \tau w^{B}>w^{A}
$$


Proposition 2 (Sufficient conditions for all migrants to return the home country $A$ ) All migrants decide to return, i.e. $U^{j, *}>0$, if:

(i) the "normal" (percentage) wage gap $\widehat{w} \equiv \frac{w^{B}}{w^{A}}$ is strictly lower than the "normal" (percentage) rate-of-return gap $\widehat{R} \equiv \frac{R^{B}}{R^{A}}$ :

$$
\frac{\widehat{w}}{\widehat{R}} \equiv \frac{\frac{w^{B}}{w^{A}}}{\frac{R^{B}}{R^{A}}}<\frac{\tau}{h}
$$

(ii) both the "normal" wage and the "normal" rate of return are strictly lower in the host country rather than in the home country, i.e.

$$
h w^{B}<w^{A} \quad \tau R^{B}<R^{A}\left(<h R^{B}\right)
$$

Proof. Let us recall Eq. (13) from the proof of Proposition 1:

$$
U^{j, *} \equiv \underbrace{\ln \left[\frac{\tau R^{B} R^{A} w_{1}+\tau R^{B} w^{A}}{\tau R^{B} R^{A} w_{1}+R^{A} \widetilde{w^{B}}}\right]}_{[1]}+\underbrace{\delta \ln \left[\frac{R^{A} w_{1}+w^{A}}{\tau R^{B} w_{1}+\widetilde{w^{B}}}\right]}_{[2]}
$$

By following the same steps as for Proposition 1, the term [1] is now positive if (and only if):

$$
\frac{\widehat{w}}{\widehat{R}} \equiv \frac{\frac{w^{B}}{w^{A}}}{\frac{R^{B}}{R^{A}}}<\frac{\tau}{h}
$$

Hence, a necessary condition for the previous inequality to hold is:

$$
\widehat{w}<\widehat{R}
$$

since $\tau<h$.

By using inequality (15) and the same steps as in Proposition 1, it is easy to show that the term [2] is certainly negative if (and only if):

$$
R^{A} \widehat{w} \tau a^{j} \underbrace{(\tau \widehat{R}-1)}_{[\mathcal{A}]}<\underbrace{(1-h \widehat{w})}_{[\mathcal{B}]}
$$

A sufficient condition such that the previous inequality holds is that term $[\mathcal{A}]$ is negative and term $[\mathcal{B}]$ is positive, which occurs respectively if:

$$
\tau \widehat{R}<1 \quad \Rightarrow \quad \widehat{R}<\frac{1}{\tau}
$$


and

$$
h \widehat{w}<1 \quad \Rightarrow \quad \widehat{w}<\frac{1}{h}
$$

Since $\widehat{w}$ must be lower than $\widehat{R}$ for term [1] to be positive, then both conditions are satisfied if:

$$
\frac{1}{h}<\widehat{R}<\frac{1}{\tau} \quad \text { and } \quad \widehat{w}<\frac{1}{h}
$$

Hence, Propositions 1 and 2 show the sufficient conditions on wages and rate of returns such that the sign of $U^{j, *}$ is always negative or always positive, i.e. such that migrants respectively decide never to return or always to return.

However, such sufficient conditions are not easy to satisfy. For instance, in the special case of equal "normal" rates of returns $-R^{A}=R^{B}$ - the Propositions 1 and 2 never hold when the "normal" wage in the host country is greater than the "normal" wage in the home country, i.e. $w^{B}>w^{A}$, which is the most common case also in reality.

Instead, when migrants are able to circumvent the effect of the skill waste only in the financial markets and rates of return are equalized net of the skill waste i.e. $R^{A}=\tau R^{B}$ - then the decision where to work depends exclusively on the total flow of income in the two locations. Since the migrant starts in the host country under both cases, the decision regards only income from period 2. The migrant decides (not) to return if and only if: $w^{A}>\widetilde{w^{B}}\left(w^{A}<\widetilde{w^{B}}\right)$, with no role played by the individual skills.

Notwithstanding these special instances, in the most general case the two propositions show that commonly the sign of $U^{j, *}$ is not uniquely defined. Among all the parameters that denote the sign of the net utility, we pay particular attention to the skill content, represented by $a^{j}$.

In particular, the derivative of the net indirect utility $U^{j, *}$ with respect to $a^{j}$ is the following:

$$
\frac{\partial U^{j, *}}{\partial a^{j}}=\frac{(1+\delta) \tau w^{B}}{W_{R} W_{N R}}\left(h R^{A} w^{B}-\tau R^{B} w^{A}\right)
$$

where $W_{R} \equiv R^{A} w_{1}^{j}+w^{A}$ and $W_{N R}=\tau R^{B} w_{1}^{j}+\widetilde{w^{B}}$.

Proposition 3 shows that under general conditions on the relative wages $\widehat{w}$ and the relative rates of return $\widehat{R}$, a greater number of highly skilled illegal migrants are more likely to return.

Proposition 3 If the "normal" (percentage) wage gap $\widehat{w} \equiv \frac{w^{B}}{w^{A}}$ is strictly higher than the "normal" (percentage) rate-of-return gap $\widehat{R} \equiv \frac{R^{B}}{R^{A}}$, i.e. 


$$
\frac{\widehat{w}}{\widehat{R}} \equiv \frac{\frac{w^{B}}{w^{A}}}{\frac{R^{B}}{R^{A}}}>1
$$

then, net utility from return migration - therefore the probability of returning in the home country - is an increasing function of the individual level of skills.

\section{Proof.}

When taking the first derivative of the net utility from return migration, we obtain:

$$
\frac{\partial U^{j, *}}{\partial a^{j}}=\frac{(1+\delta) \tau w^{B}}{W_{R} W_{N R}}\left(h R^{A} w^{B}-\tau R^{B} w^{A}\right)
$$

where $W_{R} \equiv R^{A} w_{1}^{j}+w^{A}$ and $W_{N R}=\tau R^{B} w_{1}^{j}+\widetilde{w^{B}}$.

The net utility is then strictly increasing in the skill level $a^{j}$ if and only if:

$$
h R^{A} w^{B}>\tau R^{B} w^{A}
$$

or:

$$
\frac{\widehat{w}}{\widehat{R}} \equiv \frac{\frac{w^{B}}{w^{A}}}{\frac{R^{B}}{R^{A}}}>\frac{\tau}{[(1-\gamma) \tau+\gamma]}
$$

Notice that, since $\gamma$ is a probability, then $h$ is a linear combination between $\tau$ (which is lower than 1) and 1. Hence, the fraction on the right-hand-side is certainly lower than 1 .

As a consequence, the condition:

$$
\frac{\widehat{w}}{\widehat{R}} \equiv \frac{\frac{w^{B}}{w^{A}}}{\frac{R^{B}}{R^{A}}}>1
$$

is sufficient to assure that $U^{j, *}$ is increasing in $a^{j}$.

This result is particularly important since it highlights how the effect of illegality as a skill waste, in both the labor market and the accession of financial markets, induces highly skilled migrants to leave the host country. While our current simple framework does not allow us to make general inferences regarding overall welfare, it seems reasonable to assume that illegality costs the host country, as it induces the more productive individuals to leave first.

The net utility is also a decreasing function of the probability of legalization, as the first derivative of $U^{j, *}$ with respect to $\gamma$ proves: 


$$
\frac{\partial U^{j, *}}{\partial \gamma}=-\frac{(1+\delta)(1-\tau) w^{B}}{\tau R^{B} w_{1}^{j}+\widetilde{w^{B}}}
$$

As intuitively expected, better prospects for period 2 increase the expected income from staying in the host country and reduce the incentives to return.

These latter two results are the main objectives of the empirical analysis, preceded by a presentation of the data set, in the following sections.

\section{B Categories of irregular aliens defining an "il- legal migrant" in the survey}

The observational unit of the survey — generally defined "illegal immigrant" is identified according to the legal status of the immigrants and in our study we consider the following four categories:

1. clandestine migrants, i.e. a foreigner with an expired (or no) visa that has been in Italian territory for no longer than 6 months and that is present in typical migrant meeting points, like "soup kitchens", orientation activities provided by voluntaries and NGOs, etc.

2. individuals applying for asylum or refugee status, i.e.:

- individuals under temporary protection for humanitarian aid;

- individuals that should be repatriated to a country where they would be persecuted for reasons concerning race, gender, language, religion, opinions, citizenship, personal or social condition or that would be repatriated to a country where they would not be protected from prosecution (the Italian reference in the law is: ex art.19, $1^{\circ}$ comma, D.lgs. no.286/98);

3. individuals waiting for a rejection decree with accompaniment to the closest border; the rejection decree is usually issued by the local police authority (Questore) to an individual that arrived in Italy avoiding border controls and that was stopped immediately after her/his arrival;

4. individuals waiting for an expulsion decree: the decree is issued by the local administrative authority (Prefetto) when the migrant avoided border controls and was not yet rejected;

In our econometric study we used only the first two categories. 


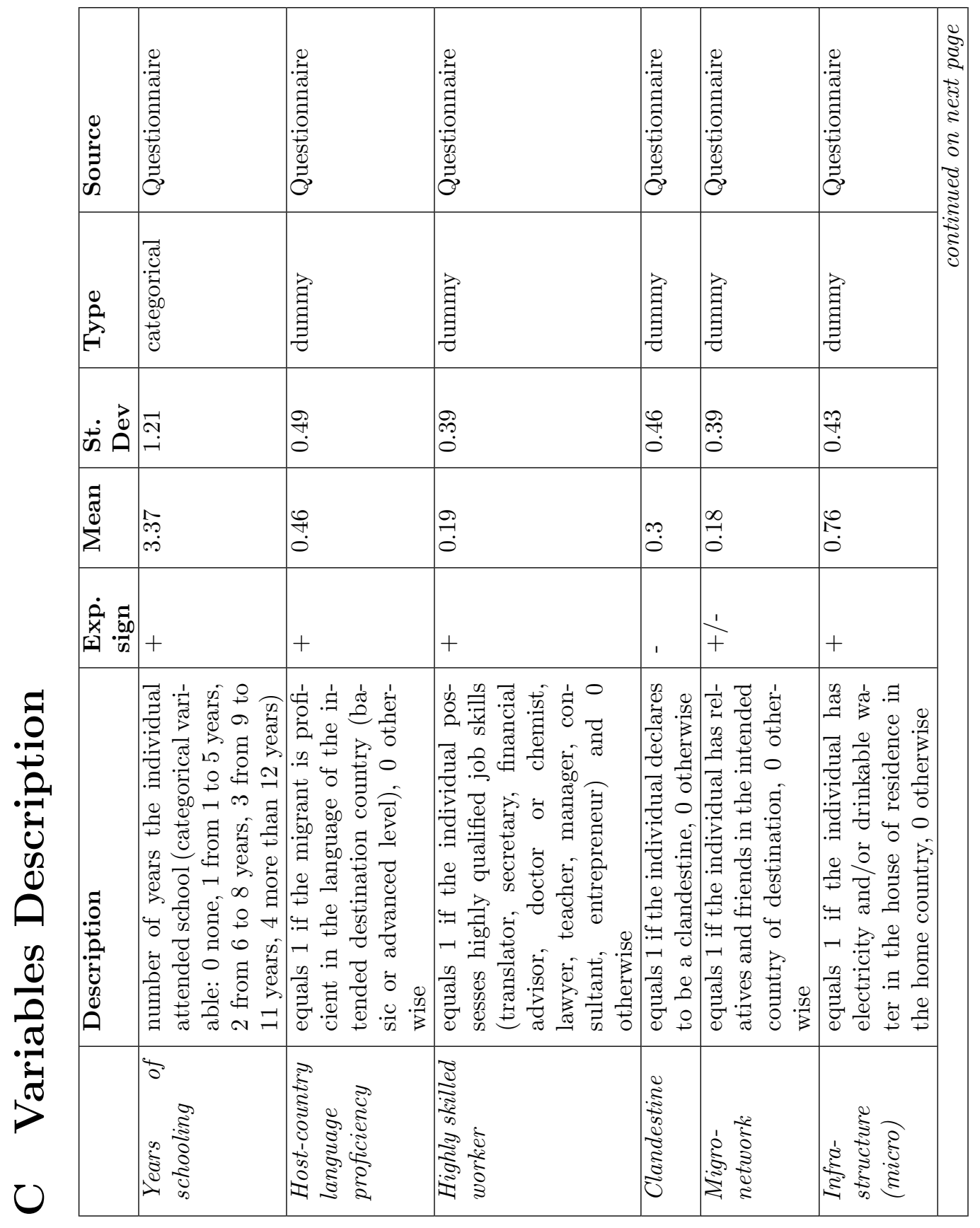




\begin{tabular}{|c|c|c|c|c|c|}
\hline I & 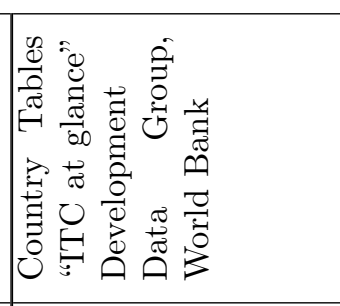 & 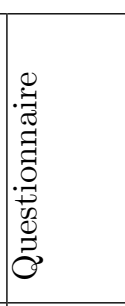 & 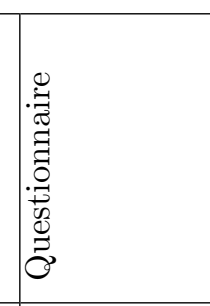 & 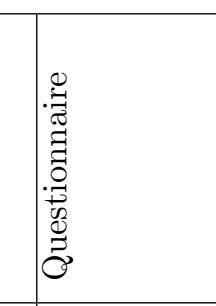 & 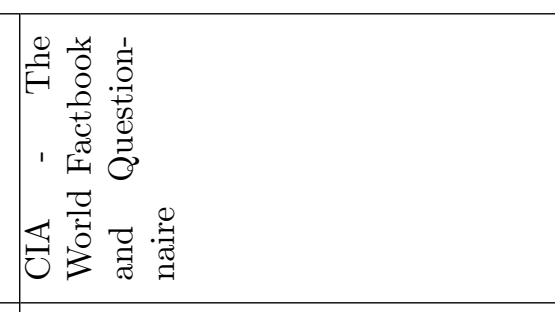 \\
\hline 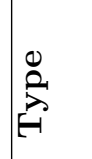 & 竞 & 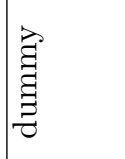 & 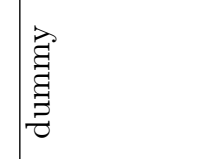 & 害 & 空 \\
\hline$\dot{i s}$ & $\widehat{\widehat{c}}$ & $\stackrel{20}{0}$ & $\begin{array}{l}0 \\
0 \\
0\end{array}$ & $\overrightarrow{0}$ & 范 \\
\hline 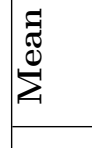 & $\stackrel{0}{0}$ & 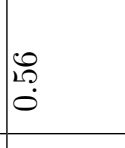 & 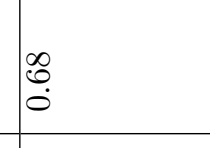 & 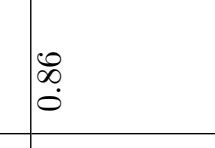 & 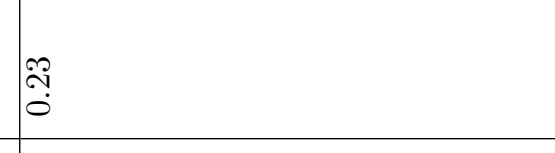 \\
\hline $\begin{array}{l}\dot{\vec{x}} \\
\dot{x} \\
\dot{y}\end{array}$ & 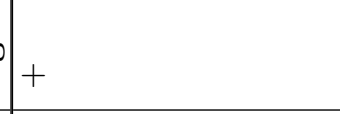 & & & $\frac{1}{+}$ & \\
\hline 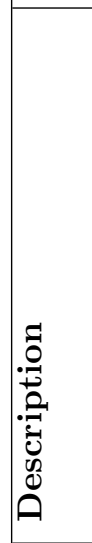 & 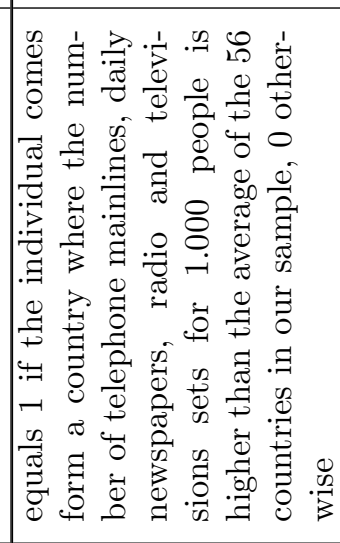 & 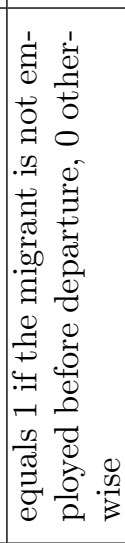 & 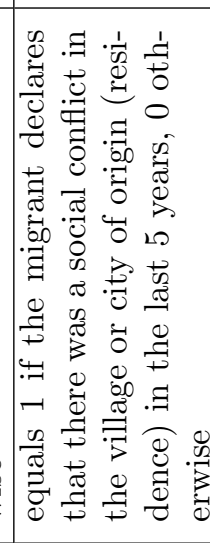 & 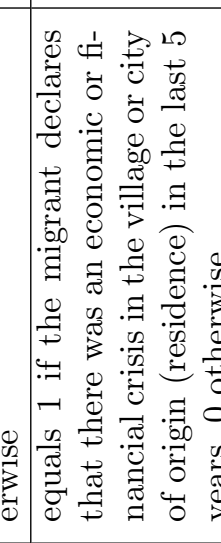 & 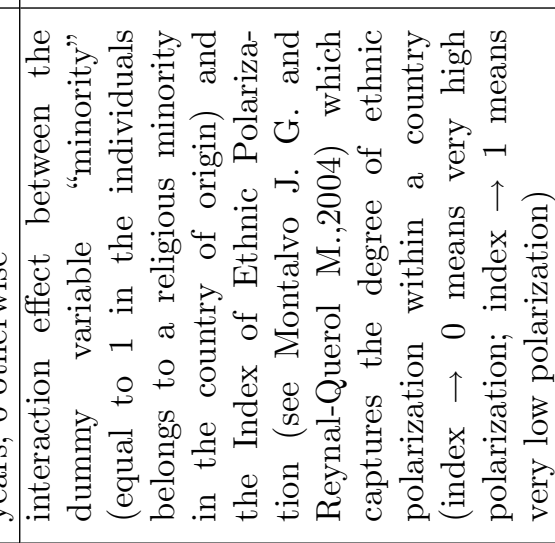 \\
\hline & 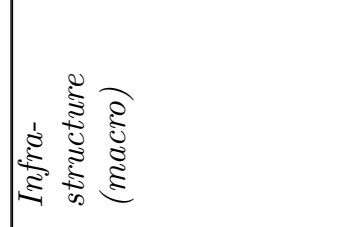 & 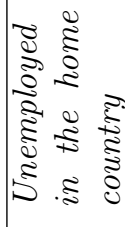 & 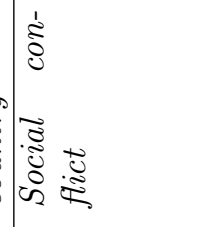 & 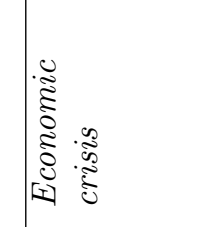 & 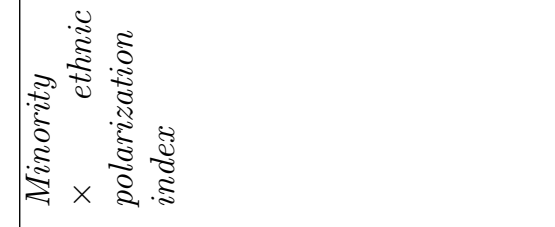 \\
\hline
\end{tabular}




\begin{tabular}{|c|c|c|c|c|c|c|c|c|c|}
\hline 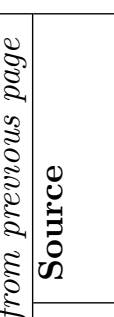 & 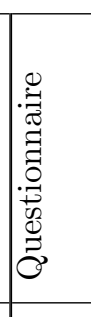 & $\mid$ & 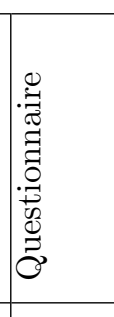 & 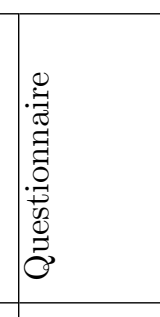 & 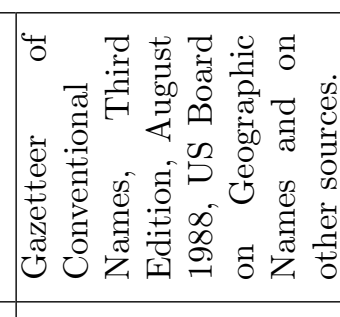 & 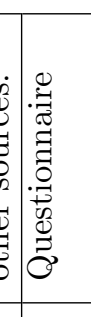 & 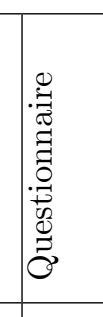 & 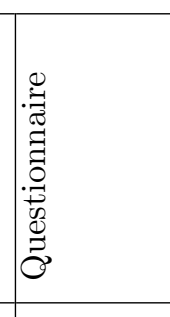 & 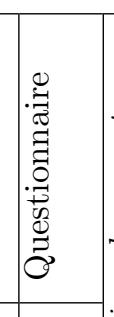 \\
\hline 离 & 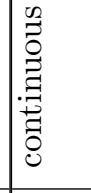 & 害 & 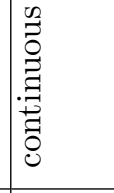 & 空 & 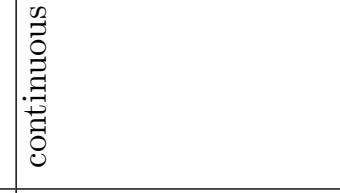 & 空 & 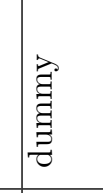 & 育 & 害 \\
\hline$\dot{\vec{d}} \overrightarrow{\mathrm{d}}$ & $\exists$ & تֶ. & $\begin{array}{l}\infty \\
\infty \\
\infty\end{array}$ & $\begin{array}{l}\mathbb{F} \\
0 \\
0\end{array}$ & $\hat{\circ}$ & I্ & 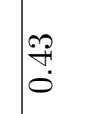 & $\vec{g}$ & 莣 \\
\hline 苛 & $\stackrel{0}{\circ}$ & : & $\stackrel{1}{10}$ & 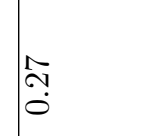 & 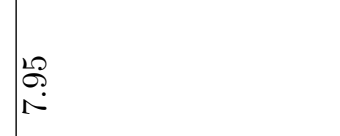 & 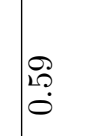 & 象 & $\overrightarrow{7}$ & 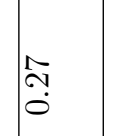 \\
\hline 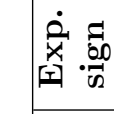 & & & & I & + & , & + & + & 1 \\
\hline 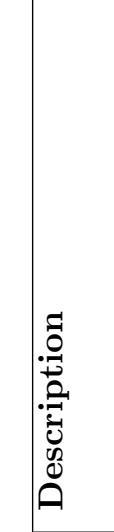 & 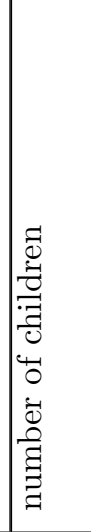 & 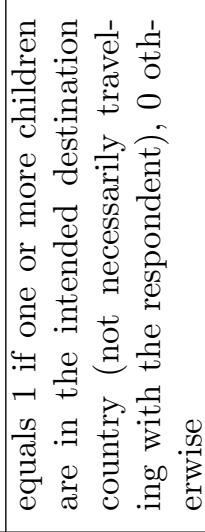 & 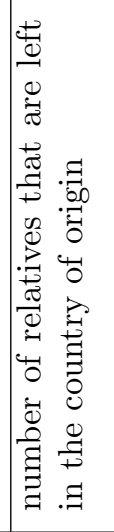 & 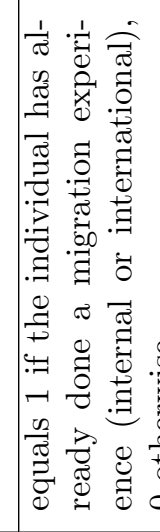 & 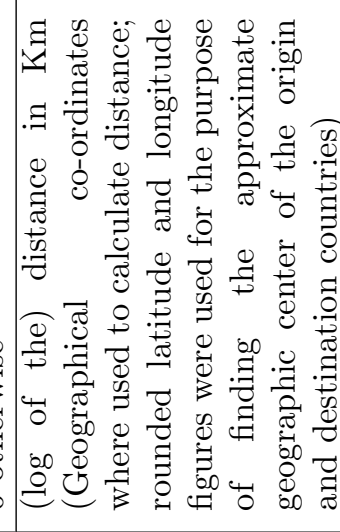 & 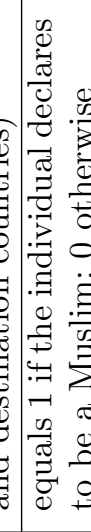 & 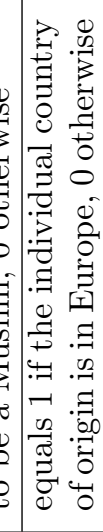 & 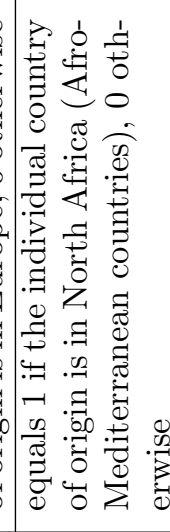 & 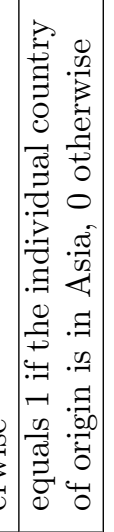 \\
\hline & 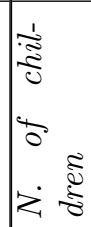 & 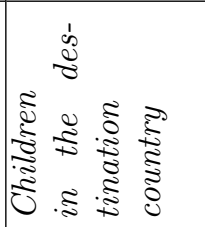 & $\approx \approx$ & 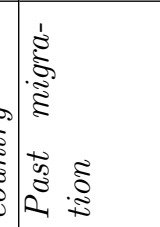 & 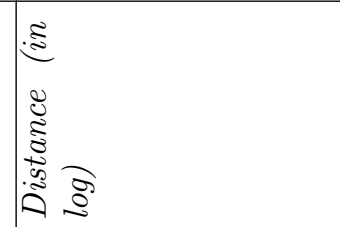 & 童 & 挋 & 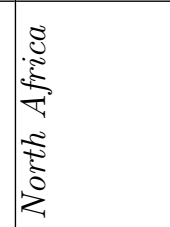 & 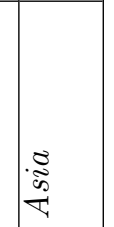 \\
\hline
\end{tabular}




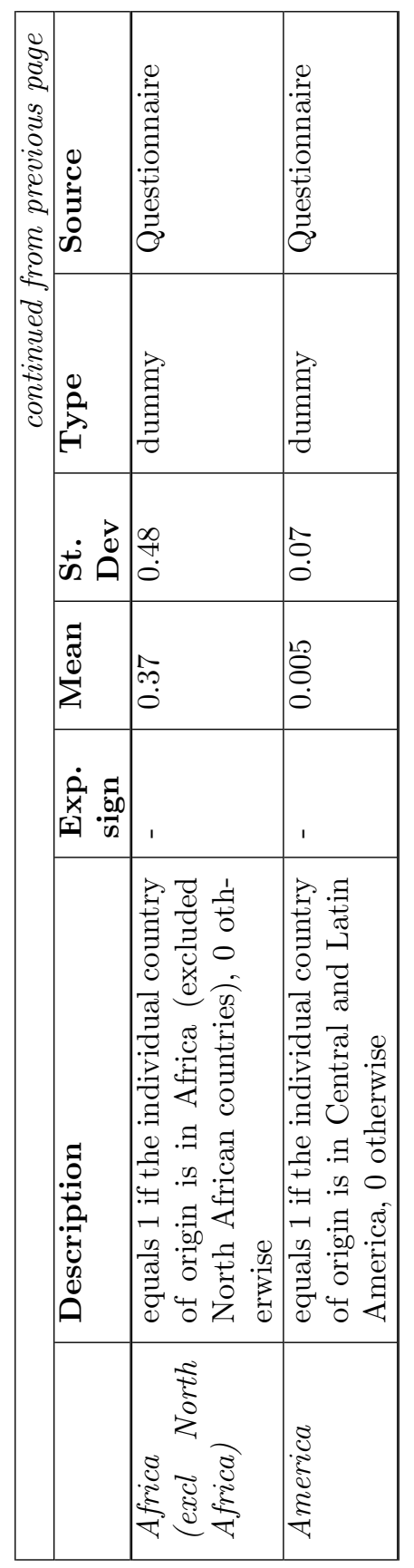


Table 4: Estimates of the Probit Model: Different Specifications

\begin{tabular}{|c|c|c|c|c|c|}
\hline Regressors & Model 1 & Model 2 & Model 3 & Model 4 & Model 5 \\
\hline \multicolumn{6}{|l|}{ Skills and network } \\
\hline Years of schooling & $\begin{array}{c}0.163^{* *} \\
(0.045)\end{array}$ & & & & \\
\hline \multirow[t]{2}{*}{ Host-country language proficiency } & & $0.340^{* *}$ & & $0.387^{* *}$ & $0.313^{* *}$ \\
\hline & & $(0.081)$ & & $(0.09)$ & $(0.083)$ \\
\hline \multirow[t]{2}{*}{ Highly skilled worker } & & & $0.439^{* *}$ & & $0.503^{* *}$ \\
\hline & & & $(0.156)$ & & $(0.187)$ \\
\hline \multirow[t]{2}{*}{ Migronetwork } & $0.395^{* *}$ & $0.426^{* *}$ & $0.442^{* *}$ & $0.604^{* *}$ & $0.538^{* *}$ \\
\hline & $(0.151)$ & $(0.154)$ & $(0.148)$ & $(0.215)$ & $(0.172)$ \\
\hline Migronetwork ${ }^{*}$ Language Prof. & & & & $\begin{array}{r}-0.239 \\
(0198)\end{array}$ & \\
\hline Migronetwork*High Skill Worker & & & & & $\begin{array}{c}-0.690^{+} \\
(0.367)\end{array}$ \\
\hline \multicolumn{6}{|l|}{ Individual covariates } \\
\hline \multirow[t]{2}{*}{ Unemployed in the home country } & $-0.239^{*}$ & $-0.201^{+}$ & $-0.219^{*}$ & $-0.200^{+}$ & $-0.191^{+}$ \\
\hline & $(0.11)$ & $(0.111)$ & $(0.108)$ & $(0.111)$ & $(0.111)$ \\
\hline \multirow[t]{2}{*}{ Children in the destination country } & $0.108^{*}$ & $0.096^{+}$ & $0.109^{*}$ & $0.095^{+}$ & $0.103^{+}$ \\
\hline & $(0.055)$ & $(0.056)$ & $(0.055)$ & $0.056)$ & $0.056)$ \\
\hline \multirow[t]{2}{*}{ Relatives in the home country } & $0.039^{* *}$ & $0.032^{*}$ & $0.033^{*}$ & $0.032^{*}$ & $0.034^{*}$ \\
\hline & $(0.014)$ & $(0.014)$ & $(0.014)$ & $(0.014)$ & $(0.014)$ \\
\hline \multirow[t]{2}{*}{ Past migration } & $-0.256^{*}$ & $-0.305^{*}$ & $-0.299^{*}$ & $-0.297^{*}$ & $-0.300^{*}$ \\
\hline & $(0.122)$ & $(0.121)$ & $(0.119)$ & $(0.121)$ & $(0.122)$ \\
\hline \multirow[t]{2}{*}{ Clandestine } & $0.598^{* *}$ & $0.614^{* *}$ & $0.609^{* *}$ & $0.602^{* *}$ & $0.616^{* *}$ \\
\hline & $(0.149)$ & $(0.152)$ & $(0.147)$ & $(0.152)$ & $(0.152)$ \\
\hline \multicolumn{6}{|l|}{ Country of Origin } \\
\hline \multirow[t]{2}{*}{ Infrastructure } & $0.498^{* *}$ & $0.609^{* *}$ & $0.452^{*}$ & $0.620^{* *}$ & $0.586^{* *}$ \\
\hline & $(0.18)$ & $(0.183)$ & $(0.178)$ & $(0.183)$ & $(0.184)$ \\
\hline \multirow[t]{2}{*}{ Social conflict } & $-0.453^{* *}$ & $-0.392^{* *}$ & $-0.428^{* *}$ & $-0.401^{* *}$ & $-0.389^{*}$ \\
\hline & $(0.152)$ & $(0.152)$ & $(0.148)$ & $(0.153)$ & $(0.152)$ \\
\hline \multirow[t]{2}{*}{ Economic crisis } & $0.577^{* *}$ & $0.546^{* *}$ & $0.586^{* *}$ & $0.541^{* *}$ & $0.633^{* *}$ \\
\hline & $(0.169)$ & $(0.172)$ & $(0.169)$ & $(0.172)$ & $(0.175)$ \\
\hline \multirow[t]{2}{*}{ Minority*ethn. pol. } & $-0.314^{*}$ & $-0.337^{*}$ & $-0.319^{*}$ & $-0.360^{*}$ & $-0.322^{*}$ \\
\hline & $(0.159)$ & $(0.159)$ & $(0.157)$ & $(0.161)$ & $(0.16)$ \\
\hline \multirow[t]{2}{*}{ Distance (in log) } & $0.505^{* *}$ & $0.588^{* *}$ & $0.541^{* *}$ & $0.589^{* *}$ & $0.595^{* *}$ \\
\hline & $(0.146)$ & $(0.15)$ & $(0.145)$ & $(0.15)$ & $(0.151)$ \\
\hline \multirow[t]{2}{*}{ Muslim } & $0.363^{* *}$ & $0.348^{* *}$ & $0.358^{* *}$ & $0.348^{* *}$ & $0.376^{* *}$ \\
\hline & $(0.119)$ & $(0.12)$ & $(0.117)$ & $(0.12)$ & $(0.121)$ \\
\hline \multirow[t]{2}{*}{ Asia } & $-0.908^{* *}$ & $-0.882^{* *}$ & $-0.989^{* *}$ & $-0.882^{* *}$ & $-0.926^{* *}$ \\
\hline & $(0.253)$ & $(0.259)$ & $(0.261)$ & $(0.269)$ & $(0.866)$ \\
\hline \multirow[t]{2}{*}{ Africa (excl North Africa) } & $-0.535^{*}$ & $-0.534^{*}$ & $-0.666^{*}$ & $-0.530^{*}$ & $-0.586^{*}$ \\
\hline & $(0.262)$ & $(0.864)$ & $(0.863)$ & $(0.864)$ & $(0.271)$ \\
\hline America & -1.049 & $-1.497^{+}$ & -1.097 & $-1.556^{+}$ & -1.389 \\
\hline
\end{tabular}


Table 4: continued

\begin{tabular}{|l|c|c|c|c|c|}
\hline Regressors & Model 1 & Model 2 & Model 3 & Model 4 & Model 5 \\
\hline & $(0.869)$ & $(0.269)$ & $(0.251)$ & $(0.259)$ & $(0.261)$ \\
Constant & $-4.516^{* *}$ & $-4.809^{* *}$ & $-4.246^{* *}$ & $-4.818^{* *}$ & $-4.994^{* *}$ \\
& $(1.077)$ & $(1.099)$ & $(1.055)$ & $(1.096)$ & $(1.104)$ \\
\hline \hline Observations & 684 & 686 & 703 & 686 & 686 \\
Pseudo R $R^{2}$ & 0.191 & 0.198 & 0.188 & 0.199 & 0.206 \\
Log likelihood & -373.15 & -371.74 & -386.61 & -371.03 & -367.81 \\
\hline
\end{tabular}

Standard errors in parentheses / Probability of return (baseline) $=0.630$

+ significant at $10 \% ;{ }^{*}$ significant at $5 \% ;{ }^{* *}$ significant at $1 \%$

Table 5: Marginal Effects of Model (5)

\begin{tabular}{|c|c|}
\hline Regressors & Marg. Eff. \\
\hline Host-country language proficiency & $\begin{array}{c}0.118^{* *} \\
(0.031)\end{array}$ \\
\hline Highly skilled worker & $\begin{array}{c}0.175^{* *} \\
(0.058)\end{array}$ \\
\hline Migronetwork & $\begin{array}{c}0.188^{* *} \\
(0.054)\end{array}$ \\
\hline Migronetwork*High Skill Worker & $\begin{array}{r}-0.270^{*} \\
(0.139)\end{array}$ \\
\hline Unemployed in the home country & $\begin{array}{c}-0.072^{+} \\
(0.042)\end{array}$ \\
\hline Children in the destination country & $\begin{array}{c}0.039^{+} \\
(0.021)\end{array}$ \\
\hline Relatives in the home country & $\begin{array}{c}0.013^{*} \\
(0.005)\end{array}$ \\
\hline Past migration & $\begin{array}{r}-0.115^{*} \\
(0.047)\end{array}$ \\
\hline Clandestine & $\begin{array}{c}0.220^{* *} \\
(0.050)\end{array}$ \\
\hline Infrastructure & $\begin{array}{c}0.199^{* *} \\
(0.054)\end{array}$ \\
\hline Social conflict & $\begin{array}{r}-0.141^{*} \\
(0.053)\end{array}$ \\
\hline Economic crisis & $\begin{array}{c}0.247^{* *} \\
(0.067)\end{array}$ \\
\hline Minority*ethnic polarization index & $\begin{array}{r}-0.122^{*} \\
(0.061)\end{array}$ \\
\hline Distance(in log) & $\begin{array}{c}0.225^{* *} \\
(0.057)\end{array}$ \\
\hline Muslim & $\begin{array}{c}0.142^{* *} \\
(0.046)\end{array}$ \\
\hline Asia & $\begin{array}{c}-0.354^{* *} \\
(0.095)\end{array}$ \\
\hline Africa (excl North Africa) & $-0.222^{*}$ \\
\hline
\end{tabular}

continued on next page 
Table 5: continued

\begin{tabular}{|l|c|}
\hline Regressors & Marg. Eff. \\
\hline & $(0.101)$ \\
America & $-0.486^{*}$ \\
& $(0.199)$ \\
Observations & 686 \\
\hline
\end{tabular}

Probability of return (baseline) $=\mathbf{0 . 6 3 9}$

Note: for the dummy variables the marginal effect is referred to the change from 0 to 1 .

Standard errors in parentheses

+ significant at $10 \%$; ${ }^{*}$ significant at $5 \%$; $*$ significant at $1 \%$ 